107 Royal Netherlands Institute for Sea Research

This is a postprint of:

Cyr, F., Bourgault, D. \& Galbraith, P.S. (2015). Behavior and mixing of a cold intermediate layer near a sloping boundary. Ocean Dynamics, 65, 357-374

Published version: $\underline{\mathrm{dx} . \text { doi.org/10.1007/s10236-014-0799-1 }}$

Link NIOZ Repository: www.vliz.be/nl/imis?module=ref\&refid=245844

[Article begins on next page]

The NIOZ Repository gives free access to the digital collection of the work of the Royal Netherlands Institute for Sea Research. This archive is managed according to the principles of the Open Access Movement, and the Open Archive Initiative. Each publication should be cited to its original source - please use the reference as presented.

When using parts of, or whole publications in your own work, permission from the author(s) or copyright holder(s) is always needed. 


\title{
Behavior and mixing of a cold intermediate layer near a sloping boundary
}

\author{
Frédéric Cyr • Daniel Bourgault • Peter S. \\ Galbraith
}

Received: December 11, 2014/ Accepted: date

\begin{abstract}
As in many other subarctic basins, a cold intermediate layer (CIL) is found during ice-free months in the Lower St. Lawrence Estuary (LSLE), Canada. This study examines the behavior of the CIL above the sloping bottom using a high resolution mooring deployed on the northern side of the estuary. Observations show successive swashes/backwashes of the CIL on the slope at a semi-diurnal frequency. It is shown that these upslope and downslope motions are likely caused by internal tides generated at the nearby channel head sill. Quantification of mixing from 322 turbulence casts reveals that in the bottom $10 \mathrm{~m}$ of the water column, the timeaverage dissipation rate of turbulent kinetic energy is $\epsilon_{10 \mathrm{~m}}=1.6 \times 10^{-7} \mathrm{~W} \mathrm{~kg}^{-1}$, an order of magnitude greater than found in the interior of the basin, far from boundaries. Near-bottom dissipation during the flood phase of the $\mathrm{M}_{2}$ tide cycle (upslope flow) is about four times greater than during the ebb phase (downslope flow). Bottom shear stress, shear instabilities and internal wave scattering are considered as potential boundary mixing mechanisms near the seabed. In the interior of the water column, far from the bottom, increasing dissipation rates are observed with both increasing stratification and shear, which suggests some control of the dissipation by the internal wave field. However, poor fits with a parametrization for large-scale wave-wave interactions suggests that the mixing is partly driven by more complex non-linear and/or smaller scale waves.
\end{abstract}

Frédéric Cyr

Institut des sciences de la mer de Rimouski, Université du Québec à Rimouski, Rimouski (Québec) Canada.

Current affiliation: Royal Netherlands Institute for Sea Research (NIOZ), 't Horntje (Texel), the Netherlands

E-mail: frederic.cyr@nioz.nl

Daniel Bourgault

Institut des sciences de la mer de Rimouski, Université du Québec à Rimouski, Rimouski (Québec) Canada.

Peter S. Galbraith

Maurice Lamontagne Institute, Department of Fisheries and Oceans Canada, Mont-Joli (Québec) Canada 
Keywords Turbulence - Boundary mixing - Cold intermediate layer · Lower St. Lawrence Estuary · Internal tides · Internal wave · Shear instabilities · Bottom shear stress 


\section{Introduction}

In a recent study, Cyr et al (2011) concluded that although not dominant, boundary mixing can contribute significantly to the mixing budget of the Gulf of St. Lawrence, a semi-enclosed subarctic sea located in eastern Canada. That study was carried out at the Rimouski section, a transect extending across the Lower St. Lawrence Estuary (LSLE), off Rimouski (Fig. 1) and was based on the analysis of hundreds of historical CTD profiles and approximately a thousand new turbulence profiles collected close to, and away from a sloping boundary. The study compared observations of vertical mixing rates with that inferred by the summer erosion of the cold intermediate layer (CIL), assumed to act like a horizontally-uniform passive tracer. However, mixing mechanisms were not identified. It was suggested that bottom shear stress and internal waves may be the principal mixing agents at sloping boundaries, but the behavior of the CIL where it intersects the sloping bottom was not investigated.

A first goal of the current study is therefore to examine the behavior of the CIL near sloping boundaries and the mixing mechanisms responsible for its erosion. Since numerous past studies have discussed the generation and propagation of an internal tide generated in the LSLE (e.g. Forrester, 1970, 1974; Ingram, 1979; Wang et al, 1991; Galbraith, 1992), a second objective is to quantify to what extent the CIL behavior and the mixing are controlled by internal tides. This last point is also relevant to other coastal basins since recent studies suggest that internal tides (or near-inertial waves in the absence of tides) can partly control the dynamics (stratification, shear and dissipation) and mixing of coastal basins and lakes (e.g., MacKinnon and Gregg, 2003; Carter et al, 2005; van der Lee and Umlauf, 2011; Bouffard et al, 2012).

In order to achieve these goals, a field experiment was carried out in a region where the CIL intersects the sloping bottom on the northern side of the Rimouski section. Mooring observations are first compared with the solution of the internal wave equation in order to determine if the CIL behavior near the boundary may result from internal tide forcing. Then, semi-diurnal modulation of turbulence is addressed from vertical microstructure profiler. Results suggest that different mixing dynamics are in play in the water column interior than in the near-bottom. A comparison between observations and existing mixing parametrizations is also made to give insights into the mixing mechanisms at work.

\section{Study area}

The St. Lawrence Estuary is commonly defined as the region between Québec city (just beyond the upper limit of salt intrusions) and Pointe-des-Monts, where begins the Gulf of St. Lawrence (e.g., Forrester, 1974; El-Sabh, 1979; Koutitonsky and Bugden, 1991) (Fig. 1). The estuary is generally subdivided into the Upper and Lower St. Lawrence Estuary (USLE and LSLE, respectively) by a shallow sill at the head of the Laurentian channel near Tadoussac. The deep (>290 m) Laurentian channel begins at the continental slope, runs across the Gulf and ends near Tadoussac where the total depth abruptly shallows from $325 \mathrm{~m}$ to about $50 \mathrm{~m}$ in less than $15 \mathrm{~km}$. 
The LSLE width varies from about $44 \mathrm{~km}$ at the mouth to about $13 \mathrm{~km}$ at the head. Because of its unusually large width for an estuary (about five times the internal Rossby radius) and because its water masses properties are similar to the Gulf of St. Lawrence, the LSLE is also commonly considered to be part of the Gulf. In winter, the major part of the Gulf of St. Lawrence is characterized by two water masses: a surface layer near the freezing point and a warmer and saltier deep layer of oceanic origin. For the rest of the year, the system is stratified into three water masses after a surface layer is formed as a result of the spring freshet and increasing air temperature. The previous winter surface layer then becomes trapped as a CIL between two warmer layers (e.g., El-Sabh, 1979; Koutitonsky and Bugden, 1991; Galbraith, 2006; Smith et al, 2006; Cyr et al, 2011). Once regenerated during the winter, the CIL properties are slowly eroded during summer months as a result of mixing (in the estuary, its core temperature warms at a rate of $\sim 0.24{ }^{\circ} \mathrm{C}$ per month while its thickness decrease at a rate of $\sim 11 \mathrm{~m}$ per month; Gilbert and Pettigrew, 1997; Cyr et al, 2011). Because of winter low surface layer salinities in the LSLE that inhibit mixing and convection, the CIL is not formed there but is rather advected from the Gulf during the summer months as the result of the estuarine circulation (e.g., Galbraith, 2006; Smith et al, 2006).

The large dimensions of the LSLE also support the generation of internal tides. These are generated at the sill near the head of the Laurentian channel and emanate seaward out of the estuary (e.g. Forrester, 1970, 1974; Ingram, 1979; Wang et al, 1991; Galbraith, 1992). Forrester (1974) was first to describe the internal tide by fitting density elevation observations to theoretical vertical modal structures in the LSLE. He found that at the $\mathrm{M}_{2}$ frequency, the internal tide to be consistent with a Poincaré-type wave in the second vertical and first horizontal modes with a wavelength of about $60 \mathrm{~km}$ along-channel. He also found evidence of Kelvin waves at the diurnal frequency. Wang et al (1991) focused on the evolution of the internal tide energy field along the estuary with three moorings along the LSLE. They suggested that after its generation at the sill, the semi-diurnal internal tide propagates with decaying amplitude, typically with vertical isopycnal displacements from about $80 \mathrm{~m}$ at the generation site to about $30 \mathrm{~m} 140 \mathrm{~km}$ downstream, i.e. $40 \mathrm{~km}$ downstream of the Rimouski section.

\section{Datasets and Methodology}

\subsection{Mooring data}

A mooring was deployed between September 20 and October 12, 2011 on the $83 \mathrm{~m}$ isobath of the north shore of the estuary (N080, Fig. 1), in a region where the bottom slope is approximately constant at $3 \%$ from $40 \mathrm{~m}$ to $120 \mathrm{~m}$. It was equipped with one Acoustic Doppler Current Profiler (RDI Workhorse ADCP, $600 \mathrm{kHz}$ ) at $59 \mathrm{~m}$ depth, looking downward to the bottom, and 8 RBR Ltd thermistors between $30-79 \mathrm{~m}$. Thermistors at 30, 40 and $50 \mathrm{~m}$ depth were equipped with pressure sensors (model TDR-2050), while the others $(60,65,70,75,79 \mathrm{~m}$ ) only measured temperature (model TR-1060). The mooring summary is provided in Table 1. All thermistors are expected to have a precision better than $0.01^{\circ} \mathrm{C}$. Raw velocity measurements have an error (defined as the statistical standard deviation on measurements) of $8.1 \mathrm{~cm} \mathrm{~s}^{-1}$ on each 3 second ensemble. Currents have been rotated 
by $-33.5^{\circ}$ to produce along-shore $(u)$ and cross-shore $(v)$ velocities. Velocities in the bottom $1.5 \mathrm{~m}$ above the sea bed have been discarded to avoid side-lobe contamination of the near bottom velocity field. Unless otherwise specified, current velocities have been smoothed using a 5 -minute averaging window to reduce the error to $1.4 \mathrm{~cm} \mathrm{~s}^{-1}$.

\subsection{Fine- and micro-structure data}

Turbulence measurements were collected during summers 2009-2012 with two freefall, loosely-tethered, vertical micro-structure profilers (VMP500) manufactured by Rockland Scientific International (RSI). Along with other sensors, these profilers are equipped with two airfoil shear probes that allow measurements of microscale $(\sim 1 \mathrm{~cm})$ vertical shear $u_{z}^{\prime}$ (see Cyr et al, 2011 , for other sensors). They are also equipped with a fine-scale $(\sim 1 \mathrm{dm})$ temperature-conductivity-depth (CTD) sensors manufactured by Sea-Bird Electronics.

A total of 1644 casts have been collected in the region. Statistics from a portion of this dataset have been published in two studies (Cyr et al, 2011; Bourgault et al, 2012). For the purpose of this study, 322 casts collected over the northern boundary of the channel during summers 2010-2012 are considered (see Fig. 1). For all these casts, the VMP hit the sloping bottom at depths varying from $20 \mathrm{~m}$ to $110 \mathrm{~m}$ ( $>80 \%$ in the $60-110 \mathrm{~m}$ range).

An Acoustic Doppler Current Profiler (RDI Workhorse ADCP $300 \mathrm{kHz}$ or $600 \mathrm{kHz}$ ) was mounted overboard of the small craft boat used to collect the turbulence profiles, at about $1 \mathrm{~m}$ below the surface and looking downward. Although the vertical bin size and the ensemble length were variable between sorties, the ADCP data were averaged into 4-m bins and 5-minute time intervals during post-processing. The error for these averaged measurements is expected to equal or less than $1.4 \mathrm{~cm} \mathrm{~s}^{-1}$. This allows the calculation of the mean shear $\left(S^{2}=\right.$ $\left.\overline{\left(\frac{\partial u}{\partial z}\right)^{2}}+\overline{\left(\frac{\partial v}{\partial z}\right)^{2}}\right)$. Approximate noise level on the shear determined from spectral analysis is $S_{n}^{2} \simeq 1.3 \times 10^{-5}$ (not shown).

The dissipation rate $(\epsilon)$ of turbulent kinetic energy (TKE) was calculated from $u_{z}^{\prime}$ using standard procedures (see Cyr et al, 2011):

$$
\epsilon=\frac{15 \nu}{2} \overline{\left(u_{z}^{\prime}\right)^{2}}
$$

where $\nu=f(T)$ is the kinematic molecular viscosity as function of temperature and the overline indicates here a vertical $1 \mathrm{~m}$ bin average. The shear variance $\overline{\left(u_{z}^{\prime}\right)^{2}}$ was obtained by spectral integration to remove random noise.

Turbulent diffusivity was calculated from the dissipation rate and stratification as:

$$
K=\frac{\Gamma \epsilon}{N^{2}} .
$$

Here $N^{2}=\frac{g}{\rho} \frac{\partial \rho}{\partial z}$ (with the depth $z$ defined positive downward), the background buoyancy frequency squared, sorted to remove density inversions and averaged in 1-m bins to match $\epsilon$ resolution, and $\Gamma$ is an indicator of the mixing efficiency, which we will refer here as the flux coefficient, according to Smyth et al (2001). 
A common practice is to calculate the diffusivity using the constant flux parameter $\Gamma=0.2$ (e.g., Osborn, 1980; Moum et al, 2002, 2004; Burchard, 2009; Holtermann et al, 2012). On the other hand, Shih et al (2005) proposed a parametrization for the mixing efficiency that depends on the turbulent activity, or the buoyancy Reynolds number ( $R e_{b}=\frac{\epsilon}{\nu N^{2}}$ ), leading to mixing efficiency significantly lower than $\Gamma=0.2$ when the turbulence is fully developed $\left(\operatorname{Re}_{b}>100\right)$. This parametrization, tested by Fer and Widell (2007) and recently used by van der Lee and Umlauf (2011) for the coastal ocean has the form:

$$
\Gamma= \begin{cases}2 R e_{b}^{-\frac{1}{2}} & \text { if } R e_{b}>100 \\ 0.2 & \text { otherwise }\end{cases}
$$

The applicability of this parametrization on microstructure observations has recently been called into question by Gregg et al (2012) who opted for the traditional constant value until some contradictions with oceanic observations were resolved. Here we present the result of both parametrizations, although diffusivity values discussed in the text have been calculated using $\Gamma=0.2$, consistent with previous studies in this area (Cyr et al, 2011; Bourgault et al, 2012). Averaged values for turbulent variables presented in this study $\left(N^{2}, S^{2}, \epsilon, K\right.$ and $\left.E_{a}\right)$, were calculated assuming log-normal distributions (Baker and Gibson, 1987).

\subsection{Phase averaging}

Hourly tide levels were obtained using the xtide software (www.flaterco.com/xtide) for the city of Rimouski. These predictions are based on harmonic analyzes of archived water level records and do not take into account storm surges or other meteorological effects. Over the three-week mooring deployment, the predicted high and low tides were off by at most two minutes with the observations (not shown).

Some of the temperature and current data presented in this study are plotted relative to the $\mathrm{M}_{2}$ tidal cycle. To do so, the closest high tide was first identified for each measurement (cast or mooring current profile). Then, the $\mathrm{M}_{2}$ period (12.42 hours) was split into 13 classes relative to the time of the closest high tide $(t=[-6,-5,-4, \ldots, 4,5,6] \mathrm{h})$ and the mean value or profile for each class was calculated. Positive and negatives classes correspond respectively to ebb and flood phases of the tidal cycle.

\section{Observations}

4.1 Cold intermediate layer behavior at the slope

An overview of temperature and velocity fields for the mooring deployment duration is presented in Figure 2. Temperature and velocities are low-pass filtered with a 25-hour cut-off period to highlight sub-tidal dynamics. The CIL is defined here as water temperature below $1^{\circ} \mathrm{C}$ (Cyr et al, 2011) and is contoured in Figure $2 b$ with a thick black line. The CIL exhibited large $(>10 \mathrm{~m})$ vertical displacements and temperature fluctuations on weekly periods, and sometimes even disappeared 
for a few days before reappearing later on. The origin of these fluctuations is not known and they may originate from horizontal advection of CIL inhomogeneities associated with changes in low-frequency circulation as suggested by panels $c$ and $d$. In the along-shore direction (panel $c$ ), the advection from the Gulf towards the estuary was variable, with a maximum inland current of about $10 \mathrm{~cm} \mathrm{~s}^{-1}$ around 24 September and a maximum seaward current of about $5 \mathrm{~cm} \mathrm{~s}^{-1}$ around 6 October. To a lesser extent, currents were also variable in the cross-shore direction (panel $d$ ), with most of the subtidal advection at this depth towards the interior of the channel, although a few pulses towards the shore are also visible. It is however difficult to draw any conclusions about these current fluctuations based on such relatively short-term observations. Possible explanations may however include Kelvin or other topographic waves that could have been generated seaward and travelled on this side of the channel. Such waves have already been observed in the LSLE with periods of about 5-8 days for the lowest modes (Lie and El-Sabh, 1983; Mertz and Gratton, 1990).

Figure 3 focusses on tidal oscillations and presents a snapshot of a timeseries encompassing about 6 semi-diurnal $\left(\mathrm{M}_{2}\right)$ tidal cycles. Isotherms exhibit large oscillations at this frequency with displacements reaching up to $40 \mathrm{~m}$. Pockets of warm water, up to $2^{\circ} \mathrm{C}$, also appear semi-diurnally and alternatively below and above the CIL. While the warm waters seen above the CIL may have arisen from vertical isotherm heaving, the source of the near-bottom waters must come either from longitudinal (along-shore) or lateral (cross-shore) advection. It will be shown in Section 4.2 that this signal may be partly explained by an internal tide that causes a periodic swash/backwash flow of warm, sub-CIL water on the slope.

This semi-diurnal pattern is now examined using the whole dataset averaged relative to the $\mathrm{M}_{2}$ tidal cycle (Fig. 4). In the along-shore direction (Fig. 4b), the currents near the bottom reverse earlier than those above, near $t \sim 0 \mathrm{~h}$ at the bottom compared to $t \sim 1.5 \mathrm{~h}$ at $20 \mathrm{~m}$ hab. Baroclinic forcing induced by internal tides may be responsible for such a lag. The mean velocity profile in this direction exhibits a log-type profile, typical of a flow above a rigid bottom, with about $5 \mathrm{~cm} \mathrm{~s}^{-1}$ in the upstream direction at $20 \mathrm{~m}$, decreasing towards $0 \mathrm{~cm} \mathrm{~s}^{-1}$ at the bottom. In the cross-shore direction (Fig. 4c), upslope currents occur during the flood and the in the early ebb for flow above $15 \mathrm{~m}$ hab. Again, over the averaged $\mathrm{M}_{2}$ cycle, it is possible to see that the upslope flow arises in successive pulses as shown in Figure 3. The mean velocity profile of the flow over the mooring duration is toward the south shore (downslope) at about $1 \mathrm{~cm} \mathrm{~s}^{-1}$. The CIL also disappears during the averaged $\mathrm{M}_{2}$ cycle. This can also be seen in Figure 3 when the CIL thickness decreases and sometimes disappears. The reason for this behavior will be examined in the next subsection.

Spectral analysis reveals that although most of the variance in temperature and along- and cross-shore velocities is at the $\mathrm{M}_{2}$ frequency, higher harmonics are also present in all fields (Fig. 5ab). To distinguish between currents in the bottom boundary layer and above (BBL thickness is estimated to be about $10 \mathrm{~m}$ thick later in the study, e.g., Fig. 9), spectral analyses were performed for different depth ranges $(0-10 \mathrm{~m}$ and $10-20 \mathrm{~m} \mathrm{hab})$. For both depth ranges, the $\mathrm{M}_{2}$ variance level largely dominated the along-shore velocities spectra (black curves), generally by two orders of magnitude above the second most important harmonic $\left(\mathrm{M}_{4}\right)$. The cross-shore velocities spectra (blue curves) are however only slightly dominated by $\mathrm{M}_{2}$. For example, the variance levels in near bottom cross-shore velocities (Fig.5a, 
blue line) is nearly as high at $\mathrm{M}_{6}$ than at $\mathrm{M}_{2}$ (about a two-fold change) and variance at $M_{8}$ is nearly as high as at $M_{4}$. For the $10-20 \mathrm{~m}$ depth range, variance level at $\mathrm{M}_{4}, \mathrm{M}_{6}$ and $\mathrm{M}_{8}$ are almost equal and less than an order of magnitude lower than $\mathrm{M}_{2}$ (Fig.5b, blue line). This reveals that the higher harmonics are relatively more important for $v$ compared to $u$, consistent with the observation of successive pulses in the cross-shore velocities discussed above and visible in Figures $3 c$ and $4 c$

It is not surprising that $u$ spectra are dominated by $\mathrm{M}_{2}$ considering the importance of the barotropic semi-diurnal tide for the LSLE (Godin, 1979; El-Sabh, 1979; Saucier and Chassé, 2000). The fact that the energy of higher harmonics is different between $u$ and $v$ raises the hypothesis that forcings responsible for the along- and cross-shore motions at our sampling site may be different. Other than the barotropic tides, one mechanism that could drive motions at tidal frequencies are internal tides. Their role as the main driver for cross-shore velocities inducing vertical motions over the sloping boundary will be addressed in Section 4.2.

Such tidal flows over a rigid bottom induce shear in the water column by friction with the seafloor. This shear $\left(S^{2}\right)$ is captured by the mooring and, as expected, is higher within the 10 -m thick bottom layer, with intensification roughly at the end of both the flood and the ebb (Fig. $4 d$ ). Spectral analysis of the shear at two different depth ranges shows that it is modulated by various tidal harmonics (Fig. 5). Between 10-20 $\mathrm{m}$ hab, the total shear $\left(S^{2}\right.$, magenta) is $\mathrm{M}_{2}$-dominated, with a major contribution from along-shore shear $\left(S_{u}^{2}\right.$, black). Higher harmonics are also present in the total shear, but the cross-shore component of the shear $\left(S_{v}^{2}\right.$, blue) dominates the signal at $\mathrm{M}_{4}, \mathrm{M}_{6}$ and $\mathrm{M}_{8}$. Shear variance is greater for $0-10 \mathrm{~m}$ compared to $10-20 \mathrm{~m}$, although variance in current velocities are similar for both depth ranges (Fig. 5ab). Contribution to the shear by the along-shore component of the velocity $\left(S_{u}^{2}\right)$ is dominant over $S_{v}^{2}$ in the $0-10 \mathrm{~m}$ range, with $S_{u}^{2}$ variance at $\mathrm{M}_{2}$ and $\mathrm{M}_{4}$ being the most important harmonics.

\subsection{A model for the propagation of internal tides}

The mooring deployed on the north shore of the LSLE shows, at a semi-diurnal time period and at higher frequencies, successive upslope and downslope movements, associated with cross-shore velocities. The barotropic radius of deformation ( $R=\frac{\sqrt{g H}}{f} \sim 500 \mathrm{~km}$, using $H=300 \mathrm{~m}$ as the channel depth, $g$ the gravitational acceleration and $f$ the Coriolis parameter) is many times larger than the channel width $(W \sim 36 \mathrm{~km})$. This implies that the cross-shore velocities cannot be generated by a geostrophic adjustment of the barotropic tide entering the channel, as previously demonstrated by Forrester (1970). In some circumstances, however, the interaction of the barotropic tidal wave with coastlines irregularities can lead to barotropic Poincaré waves which have cross-shore velocities (Taylor, 1921).

To examine whether internal tides can explain the observed velocity and temperature fields, we revisit the study of Forrester (1974) who described the semidiurnal internal tide in the LSLE as being mainly a progressive Poincaré-type wave in the second vertical mode and first horizontal mode. As shown in Forrester (1974), vertical mode-1 is not allowed in the LSLE because the channel width at the generation site is too narrow. For comparison with mooring observations, this model is setup for an idealized infinite rectangular channel in the x-direction, 
with depth $H=300 \mathrm{~m}$ and width $W=36 \mathrm{~km}$. Note that Forrester (1974) used $W=25 \mathrm{~km}$, whereas we choose $W=36 \mathrm{~km}$ as width more suitable to the Rimouski section. This channel width includes the sloping boundary where the mooring is located, but excludes shallower shelves with depth $<40 \mathrm{~m}$ on either side of the channel.

Vertical displacement $\eta$ and velocities $u$ and $v$ for a Poincaré wave of vertical mode-n and horizontal mode-m are given by (see Forrester, 1974, Eq. 6):

$$
\begin{aligned}
& \eta(x, y, z, t)=\left(\sin \lambda y-\frac{\sigma \lambda}{\kappa f} \cos \lambda y\right) \eta_{0}(z) \cos (\sigma t-\kappa x) \\
& u(x, y, z, t)=\left(\frac{\sigma}{\kappa} \sin \lambda y-\frac{\lambda}{f}\left(\frac{\sigma^{2}-f^{2}}{\kappa^{2}+\lambda^{2}}\right) \cos \lambda y\right) \frac{d \eta_{0}(z)}{d z} \cos (\sigma t-\kappa x) \\
& v(x, y, z, t)=\left(\frac{f^{2} \kappa^{2}+\sigma^{2} \lambda^{2}}{f \kappa\left(\kappa^{2}+\lambda^{2}\right)} \sin \lambda y\right) \frac{d \eta_{0}(z)}{d z} \sin (\sigma t-\kappa x)
\end{aligned}
$$

Here, $\sigma$ is the frequency of the wave, taken as the $\mathrm{M}_{2}$ frequency $(\sigma=1.4053 \times$ $10^{-4} \mathrm{~s}^{-1}$ ) and $f$ is the Coriolis parameter. Note that our $x$-axis is positive downstream, opposite to Forrester's convention but consistent with the coordinate system of Figure 1. The z-axis is positive downward and $y=0$ corresponds to the southern boundary of the rectangular channel. Wavenumbers $\kappa$ and $\lambda$, respectively in the $\mathrm{x}$ - and $\mathrm{y}$-directions are related through the dispersion relation of Poincaré waves:

$$
\sigma^{2}=f^{2}+c_{n}^{2}\left(\kappa_{n m}^{2}+\lambda_{m}^{2}\right)
$$

where $c_{n}$ is the mode-dependent phase velocity of the wave that will be determined later (see Eq. A12 in the Appendix). Equation 5 indicates that a necessary condition for Poincaré waves to exist is that $\sigma>f$. Because the wave is bound by side walls in the y-direction, $\lambda_{m}=m \frac{\pi}{W}$ for the $m^{t h}$ horizontal mode of oscillation.

In order to use equations 4 , the modal vertical displacement structure $\eta_{0}(z)$ is needed. To do this, we followed Forrester (1974) and considered an idealized horizontally-uniform background density stratification given by an exponential profile of the form:

$$
\rho=\rho_{r} e^{-\left(\frac{d}{z+h}\right)} .
$$

Here, $\rho_{r}=1027.5 \mathrm{~kg} \mathrm{~m}^{-3}, d=0.0924 \mathrm{~m}$ and $h=15.4 \mathrm{~m}$. This represents a best fit to 198 CTD casts obtained in proximity of the mooring during the deployment period (Fig. 6a, gray lines). For all 1-m bins of the observed mean profile, the relative error with the fit is at most $0.03 \%$.

As shown by Forrester (1974) and re-derived here in the Appendix, such analytical density profile allows the following vertical structure for isopycnals displacement:

$$
\eta_{0}(z)=\eta_{n}\left(\frac{z}{h}+1\right)^{1 / 2} \sin \left[\frac{\ln \left(\frac{z}{h}+1\right)}{\ln \left(\frac{H}{h}+1\right)} n \pi\right]
$$


where $\eta_{n}=-3.9 \mathrm{~m}$ is an arbitrary scaling factor chosen to approximately match the observed isotherms displacements. The demonstration to obtained this structure is provided in the Appendix. The vertical structure $\eta_{0}$ for the mooring site is given in Figure $6 b$ (gray line).

Note that it is also possible to find the vertical modal structure $\eta_{0}$ by numerically solving the Poincaré waves eigenvalue problem (Eq. A1), but in this case, a full-depth (i.e. $300 \mathrm{~m}$ ) density profile would be needed. Here, the exponential coefficients were obtained by least square minimization of profiles not deeper than $\sim 110 \mathrm{~m}$, but the analytical expression was extended to $300 \mathrm{~m}$, the depth of the channel for this model (Fig. 6a, thin-gray line). Since the stratification evolves seasonally and spatially in the LSLE, this choice was the best trade-off to obtain a full depth profile that best matches the surface stratification at our sampling site. The use of a mean profile from the center of the channel during the time of our experiment (Fig. 6a, black lines) would have lead to a node position for vertical displacement at $71 \mathrm{~m}$ instead of $54 \mathrm{~m}$ (Fig. $6 b$, black line) which would not compare favorably with our observations.

Given the vertical displacement $\eta$ at any location and time, the temperature field $T(x, y, z, t)$ can be estimated as

$$
T(x, y, z, t)=T_{0}(z)-\eta \frac{d T_{0}}{d z},
$$

where $T_{0}(z)$ is the background, horizontally-uniform and time-invariant temperature profile. This background temperature profile corresponds to the mean temperature profile sampled in proximity of the mooring during the deployment period for the $0-80 \mathrm{~m}$ depth range. For illustration purposes, the temperature profile was linearly interpolated below $80 \mathrm{~m}$ to reach $5^{\circ} \mathrm{C}$ at $300 \mathrm{~m}$, the approximate climatological value. Since the temperature is used here as a tracer, this has no effect on the dynamics. This simplified model provides a framework from which the observed currents and temperature signals can be interpreted. For the purpose of this study, we limit our analysis to the cross-section corresponding to the Rimouski section. Since the solution is periodic, we assume $x=0$ at the Rimouski section.

The evolution of the temperature field given by Eq. 8 over a semi-diurnal period at the location of the numerical domain equivalent to the mooring site is given in Figure 7. Comparison between this figure and the first three panels of Figure 4 shows qualitative similarities for $T$ and $v$. Modeled along-shore velocities $u$ are weaker and not in phase with those observed (note the different colorscale used for $u$ ), but this is explained by the fact that the observed along-shore velocities are dominated by the barotropic tide. Although this calculation relies on idealized bathymetric and stratification conditions, the ressemblance between predicted and observed cross-shore velocity amplitudes and patterns supports the idea that these are at least partly due to the transverse component of the Poincaré internal tide. This model also suggests that the observed disappearance of the CIL during an average $\mathrm{M}_{2}$ cycle (Fig. 4) is the result of the pinching of the CIL by the internal tide at a vertical node (Fig. 7). The interaction between the internal tide currents and the sloping boundary may also affect the temperature evolution and may explain why the CIL often disappears, e.g., advected away from the mooring.

Only internal tides at $\mathrm{M}_{2}$ frequency were modeled here, although $\mathrm{M}_{4}, \mathrm{M}_{6}$ and $\mathrm{M}_{8}$ harmonics are also observed in cross-shore velocities (Fig. 5ab). These may be responsible for pulses in cross-shore velocities of Figure $3 c$ and $4 c$. Wang et al 
(1991) suggested that during its propagation towards the Gulf, the energy of the semi-diurnal internal tide rapidly decays and the relative importance of the higher harmonics becomes greater, leading to variance levels at $\mathrm{M}_{4}, \mathrm{M}_{6}$ and $\mathrm{M}_{8}$ nearly as high as at $\mathrm{M}_{2}$ in the cross-shore direction. The physical mechanisms that could explain this behavior are unclear. One possibility could be that these higher harmonics are locally generated by the non-linear interaction of the internal tide with the topography near the mooring. Higher harmonics in the along-shore direction are also present, but are less important relative to the variance at $\mathrm{M}_{2}$ frequency, likely reflecting the importance of the semi-diurnal barotropic tide in the LSLE.

\subsection{Mean turbulent quantities}

An example of near bottom dissipation sampled by the VMP is shown in Figure $8 a$, representing about 7 hours of consecutive sampling, i.e., our longest timeseries near the mooring location. Each of the casts realized on this occasion hit the bottom at depths varying between 74 and $91 \mathrm{~m}$. Since the boat was slowly drifting towards shallower water, it was repositioned near 16:13 UTC. Figure 8 also presents the buoyancy frequency squared $\left(N^{2}\right)$, averaged in 4 -m bins to match the shear vertical resolution computed from the outboard ADCP $\left(S^{2}\right)$. The latter was 1-hour filtered and combined to the buoyancy frequency to compute gradient Richardson number $\left(R i=\frac{\overline{N^{2}}}{\overline{S^{2}}}\right)$ that is presented here as $\tanh (R i)$ to better highlight regions below the threshold $R i=\frac{1}{4}$ (orange-red colors) where shear instabilities are expected to occur (Miles, 1961; Howard, 1961). This is useful to better visualize unstable regions $\operatorname{since} \tanh (R i) \simeq R i$ for $R i<0.5$ and $\tanh \left(R i_{\left.\right|_{R i \rightarrow+\infty}}\right)=1$.

The dissipation is generally patchy, with enhanced turbulence levels both near the seabed and in the interior. Near the seabed, a notable feature is the high dissipation rate found between 13:00-15:00, a period corresponding to the end of flood (high tide at 14:31 UTC). This period and location correspond to high shear and low $R i$. Note that although turbulence is high, the bottom boundary layer maintains its stratification $\left(N^{2}>10^{-5} \mathrm{~s}^{-2}\right)$. Further away from the bottom, turbulent layers a few meters thick that can last for hours are found. These are generally aligned with bands of high shear and low Ri. Such bands of high dissipation show strong similarities with that found in the Baltic Sea, which were attributed to shear caused by sub-inertial internal wave motions (e.g., van der Lee and Umlauf, 2011). The possible relation between shear, stratification and dissipation is examined in Section 5.3.

We summarized all similar sorties in Figure 9, where 322 VMP casts and corresponding (simultaneous) velocity and shear profiles from the outboard ADCP are presented. Highest shear (Fig. 9b, black curves) is found in the bottom $10 \mathrm{~m}$ of the water column and corresponds to a rapid decrease in the mean velocity $U=\sqrt{u^{2}+v^{2}}$ (Fig. 9a). On the other hand, the stratification $N^{2}$ (Fig. 9b, gray curves) decreases steadily from about $50 \mathrm{~m}$ to the bottom, except in the bottom $5 \mathrm{~m}$ where it slightly increases. $R i$ decreases quasi-linearly from about $50 \mathrm{~m}$ to $10 \mathrm{~m} \mathrm{hab} \mathrm{(Fig.} \mathrm{9c).} \mathrm{Between} 10 \mathrm{~m}$ and $5 \mathrm{~m}, R i$ decreases more rapidly driven by the increasing shear and falls below the threshold $R i=\frac{1}{4}$ (vertical dashed-line). In the bottom $5 \mathrm{~m}, R i$ remains almost constant and below the threshold.

The dissipation rate of TKE $(\epsilon)$ presented in Figure $9 d$ (black lines) increases toward the bottom of the water column. Flood and ebb averaged profiles are more 
or less the same until below $10 \mathrm{~m} h a b$ where $\bar{\epsilon}_{\text {flood }}\left(2.8(1.9,3.9) \times 10^{-7} \mathrm{~W} \mathrm{~kg}^{-1}\right)$ exceeds $\bar{\epsilon}_{\text {ebb }}\left(0.72(0.53,0.98) \times 10^{-7} \mathrm{~W} \mathrm{~kg}^{-1}\right)$ by about a four-fold change on average. Here numbers in parentheses are the bootstrapped $95 \%$ confidence interval on the mean value and overlines refer to a vertical average of the mean profile in the $0-10 \mathrm{~m}$ $h a b$ depth range. On average, the enhanced dissipation near the seabed during the flood is consistent with the snapshot presented in Figure 8. The average dissipation rate in the bottom $10 \mathrm{~m}$ over all casts is $\bar{\epsilon}_{10 \mathrm{~m}}=1.6(1.2,2.0) \times 10^{-7} \mathrm{~W} \mathrm{~kg}^{-1}$, an order of magnitude greater than that measured far from the boundaries and reported in Cyr et al (2011).

Mean diffusivity profiles are calculated here using both constant $(\Gamma=0.2$, black lines) and variable (Eq. 3, gray lines) mixing efficiencies. Using $\Gamma=0.2$, mean diffusivity in the bottom $10 \mathrm{~m} h a b$ gives $\bar{K}_{\text {flood }}=11(6.7,18) \times 10^{-4} \mathrm{~m}^{2} \mathrm{~s}^{-1}, \bar{K}_{\text {ebb }}=$ $2.5(1.6,3.8) \times 10^{-4} \mathrm{~m}^{2} \mathrm{~s}^{-1}$ and $\bar{K}_{10 \mathrm{~m}}=6.0(4.1,8.5) \times 10^{-4} \mathrm{~m}^{2} \mathrm{~s}^{-1}$. When calculated using the Shih et al (2005) parametrization, the average diffusivity for the bottom $10 \mathrm{~m}$ is $\bar{K}_{\text {Shih }}=6.5(5.6,7.6) \times 10^{-5} \mathrm{~m}^{2} \mathrm{~s}^{-1}$, i.e., nearly an order of magnitude lower than when using $\Gamma=0.2$. Previous studies have suggested such substantial reduction of the mixing efficiency $(\Gamma \ll 0.2)$ for energetic mixing near bottoms having slopes similar to that of our sampling site (Umlauf and Burchard, 2011; Becherer and Umlauf, 2011). However, these studies also predict considerably reduced stratification above the seafloor which is not the case in the present observations (Figure $9 b$ suggest a slight increase of the stratification in the bottom $5 \mathrm{~m}$ ). Average diffusivity calculated with the Shih et al (2005) parametrization is also inconsistent with the near bottom diffusivities inferred by inverse modeling in this area (Cyr et al, 2011).

\section{Discussion}

\subsection{CIL behavior in response to internal tides}

The study suggests that during the mooring deployment the node for vertical displacement was located near 25-30 m hab, i.e., at CIL depth (Fig. 4). Our best fit on the density profile yields a node in the solution of vertical displacement $\left(\eta_{0}\right.$, Eq. 7$)$ at $z=54 \mathrm{~m}$, i.e., $29 \mathrm{~m} \mathrm{hab}$ at mooring site (Fig. $6 b$, gray line), thus supporting the idea that the pinching of the isotherms at this depth is the reason why the CIL disappears at some phases of the $\mathrm{M}_{2}$ tide cycle.

Our study also highlights that this node position is highly variable depending on near-surface stratification. Using the density profile measured at the center of the channel instead of near the boundary to compute the second vertical modal structure would displace the node down by nearly $20 \mathrm{~m}$ (Fig. 6b, black line). With such horizontally inhomogeneous stratification, internal tides generated at the head of the Laurentian channel are thus spatially modulated during their propagation out of the estuary. This changing vertical structure thus makes any generalization concerning their behavior (node position, current amplitudes, etc.) difficult and caution should be taken in interpreting these results.

Cross-shore currents are also associated with internal tides. In our model, however, they do not interact with the real topography. In the real case of a sloping boundary, these currents could generate upslope and downslope currents. This may explain the asymmetry (maximum displacement not in phase at each depth) 
that exists in Figure $4 a$ compared to Figure $7 a$. Although $u$ and $v$ velocities are nearly in phase (upslope flow during the flood), this is fortuitous since internal tides have a wavelength in the propagation direction many times smaller than the barotropic tides. Depending on the distance from the generation site, the current reversals of internal tides do not necessarily occur in phase with the reversal of the barotropic tide that generated it. At the mooring site, the lag between barotropic high tide and cross-shore current reversal (driven by internal tides) is about $1.5 \mathrm{~h}$ (Fig. 4), about equivalent to the phase shift applied in Figure 7 for better visual comparison $\left(\phi=\frac{\pi}{4} \sim 1.5 \mathrm{~h}\right.$ for the $\mathrm{M}_{2}$ period).

Internal tides in the LSLE thus impact, at semi-diurnal and higher frequencies, the velocity, salinity, temperature and other physico-chemical property distribution. In preparation to field programs, care should be taken to not under-sample in time the water column properties that are subject to large variations due to such isopycnals heaving. For example, a CIL index based on the cold water volume (Galbraith, 2006), is used in annual reports on the physical oceanographic conditions of the Gulf of St. Lawrence (e.g. Galbraith et al, 2014). When based on a single profile, estimates that use the CIL thickness may be not representative of the mean conditions, depending on which phase of the isotherms heaving it has been realized.

\subsection{Boundary mixing in the LSLE}

From about 150 casts (not necessarily above the sloping boundary), Cyr et al (2011) reported near bottom diffusivity to be $K_{\mathrm{b}}=3.3(2.1,4.8) \times 10^{-4} \mathrm{~m}^{2} \mathrm{~s}^{-1}$. With such a diffusivity, boundary mixing was estimated to account for about one third of the mixing budget in the LSLE. When analyzed in terms of dissipation, this corresponded to $\epsilon_{\mathrm{b}}=1.2(1.0,1.4) \times 10^{-7} \mathrm{~W} \mathrm{~kg}^{-1}$ (values not reported in Cyr et al (2011)). In the present study, a more extensive sampling above the sloping bottom reveals that the average dissipation and diffusivity in the bottom $10 \mathrm{~m}$ are $\bar{\epsilon}_{10 \mathrm{~m}}=$ $1.6(1.2,2.0) \times 10^{-7} \mathrm{~W} \mathrm{~kg}^{-1}$ and $\bar{K}_{10 \mathrm{~m}}=6.0(4.1,8.5) \times 10^{-4} \mathrm{~m}^{2} \mathrm{~s}^{-1}$ (Section 4.3), thus higher than the results of Cyr et al (2011).

The study however supports the findings of Cyr et al (2011) that boundary mixing is significant at the scale of the LSLE and possibly the Gulf of St. Lawrence. Using a scaling for the effective diffusivity at the basin scale $\left(K_{\mathrm{e}}\right.$, Cyr et al, 2011, Eq. 5) with updates from this study, we suggest $K_{\mathrm{e}}=4.1 \times 10^{-5} \mathrm{~m}^{2} \mathrm{~s}^{-1}$ and reassess that boundary mixing can account for about $30-40 \%$ of this value.

Mean profiles reported in Figure 9 are also informative of the nature of turbulent processes encountered in the LSLE. For certain shallow highly stratified or partially mixed estuaries, one may expect that most of the dissipation is determined by bottom stress and stress in the pycnocline (e.g. Geyer and Smith, 1987; Geyer et al, 2000, 2010). In these estuaries, the stratification varies within a broad range of values between ebb and flood conditions with often very weak stratification during strongest tidal flow (e.g. Nepf and Geyer, 1996; Peters, 1997; Geyer et al, 2000; Kay, 2003). The LSLE does not behave such as these estuaries since even in the near bottom part of the water column the stratification remains nearly constant between the ebb and flood (Fig. 9b). Although near bottom dissipation, $\epsilon$, is modulated by the semi-diurnal tide cycle (by a four-fold change, section 4.3), the difference at each depth between the flood and ebb mean strat- 
ification profiles is always less than $1 \%$. In fact, with a mean stratification near $N \sim 10^{-2} \mathrm{~s}^{-1}$ and dissipation rate in the $\epsilon \sim\left[10^{-8}, 10^{-7}\right] \mathrm{W} \mathrm{kg}^{-1}$ range, turbulence in the LSLE falls within the continental shelf turbulence definition, following the classification of oceanic and estuarine turbulence by Geyer et al (2008) (see their Figure 1). Mixing mechanisms likely to be encountered in the LSLE are thus those usually present at the continental slope, including shear instabilities of various origin, bottom friction and internal wave induced mixing.

\subsection{Mixing mechanisms and forcings}

Our observations suggest that bottom and interior mixing processes are at work at our sampling location. The former is suggested by the high dissipation rates found near the bottom, while the latter is suggested by the higher shear and dissipation bands found in the interior of the water column (Figs. 8 and 9). These two regions will be discussed next in an attempt to identify mixing mechanisms at work and their origin (forcings).

\subsubsection{Bottom boundary region}

In this area subject to intense tidal currents, mixing by bottom shear stress resulting from the friction of the flow over the bottom may be expected to occur. For an steady homogeneous flow, the dissipation driven by bottom friction should follow a log-law scaling, commonly referred to as the law of the wall: $\tilde{\epsilon}=\frac{u_{*}^{3}}{\kappa \tilde{z}}$. Here $\kappa=0.41$ is the von Kármán constant, $\tilde{z}$ the distance from the bottom and $u_{*}=\sqrt{C_{d}} U_{\mathrm{b}}$ the friction velocity that depends on a constant drag coefficient $\left(C_{d}\right)$ and the near bottom velocity $U_{\mathrm{b}}$ (see Walter et al, 2012, for example).

Since this theory is suitable for unstratified water, we first identified near bottom profiles where buoyancy effects were not expected to affect overturning in the bottom boundary layer (BBL). This condition is expected to hold when the Ozmidov scale $\left(l_{o}=\left(\frac{\epsilon}{N^{3}}\right)^{\frac{1}{2}}\right.$, a length-scale for the size of overturns limited by stratification) is larger than the scale of the overturns limited by their distance to the bottom $(l=\kappa \tilde{z}$, the length-scale that appears in the law-of-the-wall). This condition can be written $l_{o}>\kappa \tilde{z}$ (see also, for example, Perlin et al, 2005; van der Lee and Umlauf, 2011).

The result of this condition for our sampling on 22 September 2011 is highlighted by the magenta lines in Figure 8. Such weaker stratification near the bottom was found in about $65 \%$ of the $322 \mathrm{VMP}$ casts and were not linked to any particular phase of the $\mathrm{M}_{2}$ tidal cycle (not shown). Moreover, for $90 \%$ of the time, the weakly stratified BBLs identified this way were $\leq 2 \mathrm{~m}$, and were never thicker than $6 \mathrm{~m}$. These weak stratification conditions however drive most of the near bottom dissipation as suggested by the difference between the thick and the thin gray lines in Figure $9 d$, which are respectively the average of low stratification bins and the averaged profile without them. Above $6 \mathrm{~m}$ hab (and most of the time above $2 \mathrm{~m}$ $h a b)$, the stratification will prevent growing turbulence from the bottom frictional layer.

Moreover, the dissipation profile inferred in the bottom $6 \mathrm{~m}$ using the above log-law scaling (Fig. 9d, dashed-gray line) is comparable, in magnitude, to the 
dissipation profile observed during periods of low stratification (thick-solid gray line). Here the log-law scaling was calculated using $C_{d}=3 \times 10^{-3}$ (Soulsby, 1997) and $U_{\mathrm{b}}=U_{2 \mathrm{~m}}$, the velocity measured by the moored ADCP at $2 \mathrm{~m} \mathrm{hab}$ and 15minute filtered to reduce the error on the measurements. Note that we used $U_{2 \mathrm{~m}}$ rather than the commonly used velocity at $1 \mathrm{~m} \mathrm{hab}$ to avoid the side-lobe effects of the ADCP measurements near the seabed. The use of different drag coefficients would not significantly affect this comparison because using $C_{d}=[1-5] \times 10^{-3}$ (range of values commonly found in the literature) leads approximately to a 2 fold change on $\epsilon_{\text {wall }}$. The two profiles above also compare favorably when looking at their averaged values, which are $\epsilon_{l_{o}>\kappa \tilde{z}}=7.2 \times 10^{-7} \mathrm{~W} \mathrm{~kg}^{-1}$ and $\epsilon_{\text {wall }}=$ $8.1 \times 10^{-7} \mathrm{~W} \mathrm{~kg}^{-1}$, respectively for the low stratified BBL and inferred from the log-scaling.

The fact that the dissipation inferred from near bottom velocities scales relatively well with the measured dissipation when the stratification is low suggests that most of the dissipation in the bottom $6 \mathrm{~m}$ of the water column are driven by bottom shear stress. This is also suggested by the fact that within this depth range, $S^{2}$ and $N^{2}$ (and thus $R i$ ) are approximately constant between flood and ebb, implying that shear instabilities cannot account for the difference between $\epsilon_{\text {flood }}$ and $\epsilon_{\mathrm{ebb}}$. In the same depth range, however, the mean velocity profile is however shifted towards greater values during the flood compared to the ebb, implying greater kinetic energy input to be dissipated by bottom friction. Because shear in the along-shore direction largely dominates the shear spectrum in the $0-10 \mathrm{~m}$ $h a b$ depth range (Fig. 5), we may hypothesize that the barotropic tidal currents are the main drivers for bottom shear stress mixing, although internal tides also generate near bottom shear. Conditions favorable to bottom shear stress occur in about $65 \%$ of our VMP casts, but is generally limited to the bottom $2 \mathrm{~m}$ hab. Elsewhere, the turbulence generated by bottom friction is likely suppressed by the stratification as suggested by the lower dissipation when ignoring bins having low stratification (thin gray line in Figure $9 d$ ).

In counterpart, other mechanisms besides bottom stress must explain the approximately exponential increase of the dissipation from about 25 to $5 \mathrm{~m} \mathrm{hab}$ (Fig. 9d). Such an increase, combined with the fact that the BBL is mostly stratified, suggests internal waves scattering (or bottom wave generation) as a possible mixing mechanism responsible for this near bottom mixing enhancement (Garrett et al, 1993; Toole et al, 1994; Slinn and Riley, 1996; St. Laurent, 2002). This mechanism was also recently summarized by Gregg et al (2012) for mixing above a continental slope.

\subsubsection{Interior mixing}

The localized bands of enhanced turbulence presented in Fig. 8 seems to correspond to bands of lower Richardson number, suggesting that shear instabilities are at work in the interior of the water column. These may be induced by internal shear or high-frequency internal waves locally-generated by the Poincaré internal wave (Bouffard et al, 2012). To examine a possible systematic relation between stratification, shear and dissipation, we plotted 4-m resolution bin of $\epsilon$ as function of $N^{2}$ and $S^{2}$ in a manner similar to MacKinnon and Gregg (2003), Carter et al (2005), Palmer et al (2008), Schafstall et al (2010), van der Lee and Umlauf (2011) and 
others (Fig. 10a). For this exercise, we ignored bins below $10 \mathrm{~m} h a b$, the region of the water column most likely affected by boundary processes (see corresponding shear enhancement in Figure 9b). Similarly, to ignore turbulence in the surface layer affected by atmospheric forcing, we also discarded surface first $5 \mathrm{~m}$, a range considered conservative since observations clearly do not show a mixed layer near the surface (Fig. 8b). The resulting figure is compared with the MacKinnon and Gregg (2003) parametrization, hereafter MG (Fig. 10b), a parametrization specifically designed to model mixing by wave-wave interactions in the coastal ocean, and favorably compared with observations from the New England Shelf (MacKinnon and Gregg, 2003, 2005), the Celtic Sea (Palmer et al, 2008) and the Baltic Sea (van der Lee and Umlauf, 2011). The equation for this parametrization is:

$$
\epsilon_{\mathrm{MG}}=\epsilon_{0}\left(\frac{N}{N_{0}}\right)\left(\frac{S}{S_{0}}\right)
$$

where $N_{0}=S_{0}=3 \mathrm{cph}$ (MacKinnon and Gregg, 2003) and $\epsilon_{0}=1.0 \times 10^{-8} \mathrm{~W} \mathrm{~kg}^{-1}$, chosen here so that the parametrization average matches the average of the observations.

Here, observations of $\epsilon$ and the predicted $\epsilon_{\mathrm{MG}}$ do not visually match well, although $\epsilon$ likely also increases with increasing $N^{2}$ and $S^{2}$ as suggested by the parametrization (Fig. 10a). This is supported by plotting $\epsilon$ as function of $N^{2}$ and $S^{2}$ alone (Figs. 10cd, shaded areas). Similar averages of $\epsilon_{\mathrm{MG}}$ (Figs. 10cd, dashedlines) suggest however that the dissipation increase with $N^{2}$ and $S^{2}$ is slightly overestimated by the parametrization. Such poor agreement of $\epsilon$ in the $N^{2}-S^{2}$ space but good functional dependence of $\epsilon$ with increasing $N^{2}$ and $S^{2}$ was also obtained by Carter et al (2005) and Schafstall et al (2010) in regions where mixing is partly driven by high wavenumber and non-linear internal waves. Carter et al (2005) recalled that while the MacKinnon and Gregg (2003) parametrization was developed for stable wave-wave interactions, the presence of nearby topography may induce internal wave scattering (energy transfer to higher modes) that is not taken into account by the parametrization. Note that internal wave scattering was also hypothesized in the preceding sub-section to explain the gradual increase of dissipation as the bottom is approached in the $0-25 \mathrm{~m}$ hab depth range.

Neither taken into account by the parametrization is the non-linear energy transfer from vertical mode- 2 of the Poincaré wave into higher harmonics $\left(\mathrm{M}_{4}\right.$, $\mathrm{M}_{6}, \mathrm{M}_{8}$ ) suggested from the shear spectrum in the 10-20 $\mathrm{m}$ hab range, particularly in the cross-shore direction (Fig. $5 d$ ). These higher harmonics may be generated by interaction with the nearby topography. Finally, our estimation of the scaling parameter $\epsilon_{0}=1.0 \times 10^{-8} \mathrm{~W} \mathrm{~kg}^{-1}$ is about 15 times higher than that used in the original MacKinnon and Gregg (2003) parametrization, also suggesting that some underlying physics may be missing for a direct application to a more energetic area such as the LSLE.

\section{Conclusion}

In a recent study, Cyr et al (2011) concluded that although not dominant, boundary mixing can contribute significantly to the erosion of the Gulf of St. Lawrence CIL. In the conclusion of that study, questions were raised concerning possible 
boundary mixing mechanisms. This partly motivated the deployment of the mooring at station N080, i.e. where the CIL intersects the sloping bottom. Mooring observations were completed with 322 VMP turbulence profiles down to the seabed.

CIL behavior at the slope has been depicted as alternating swashes/backwashes of the layer on the sloping boundary at a semi-diurnal frequency, with superimposed higher harmonics. At the mooring location, the CIL also thickens and shrinks (and sometimes disappears) at semi-diurnal and higher frequencies. This behavior is part of the 3-dimensional structure of internal tides generated at the head of the Laurentian channel that propagate out of the estuary. During their propagation, internal tides may possibly be degenerated by interactions with the topography, generating higher harmonics. To date, studies focusing on internal tides in the LSLE have been limited to scarce observations and idealized models, and the region still lacks a detailed description of the propagation of these tides. This description is however difficult because of the complex bathymetry and changing water stratification properties along the channel.

Observations suggest that the analysis of turbulent mixing mechanisms at the sampling site can be divided into the near-bottom and a water column interior area. Near-bottom turbulence increase with decreasing hab is partly driven by shear stress caused by the friction of the barotropic tidal currents. When currents were maximum, i.e. during flood, the dissipation rate of TKE was approximately 4 times higher than during ebb. Such strong turbulence occured in about $65 \%$ of our profiles and corresponded to periods when the maximum size of overturns in the BBL was not limited by stratification. The portion of the BBL subject to such a mechanism never exceeded $6 \mathrm{~m} h a b$ and was generally limited to the bottom $2 \mathrm{~m} h a b$. Below about $25 \mathrm{~m} h a b$ but above the weakly stratified BBL, the dissipation also increased with decreasing $h a b$, albeit to a lesser extent as the bottom was approached. Since the stratification likely suppresses turbulence growth from bottom stress in this portion of the water column, internal wave scattering may be responsible for this increase.

Dissipation rates were also compared with stratification and shear conditions in order to identify if the observed internal tides may partly explain the bandlike shear and high dissipation rates in the interior of the water column. The poor agreement between the observations and the MacKinnon and Gregg (2003) parametrization suggests that mechanisms other than stable wave-wave interactions must be at work. Since this parametrization does not account for nearby topography, the presence of the sloping boundary at our observation site may explain the discrepancies. It would be interesting, however, to compare this parametrization with observations from the interior of the basin (far from boundaries) where, as our results reassess, about two-third of the mixing budget of the LSLE take place.

Acknowledgements This work was funded by "Le Fonds de recherche du Québec - Nature et technologies", the Natural Sciences and Engineering Research Council of Canada, the Canada Foundation for Innovation and Fisheries and Oceans Canada and is a contribution to the scientific program of Québec-Océan. The authors would like to thank Remi Desmarais and Paul Nicot who were frequent crew members during our summer sampling campaigns, Leo Maas for his help with the derivation of the Poincaré wave equations, and Cédric Chavanne, Luc Rainville and two anonymous reviewers who provided valuable comments to improve this manuscript. 


\section{References}

Baker MA, Gibson CH (1987) Sampling turbulence in the stratified ocean: statistical consequence of strong intermittency. Journal of Physical Oceanography $17: 1817-1838$

Becherer JK, Umlauf L (2011) Boundary mixing in lakes: 1. Modeling the effect of shear-induced convection. Journal of Geophysical Research 116(C10):1-15, DOI 10.1029/2011JC007119

Bouffard D, Boegman L, Rao YR (2012) Poincaré wave-induced mixing in a large lake. Limnology and Oceanography 57(4):1201-1216, DOI 10.4319/lo.2012.57.4. 1201

Bourgault D, Cyr F, Galbraith PS, Pelletier E (2012) Relative importance of pelagic and sediment respiration in causing hypoxia in a deep estuary. Journal of Geophysical Research 117(C08033), DOI 10.1029/2012JC007902

Burchard H (2009) Combined effects of wind, tide, and horizontal density gradients on stratification in estuaries and coastal seas. Journal of Physical Oceanography 39(9):2117-2136, DOI 10.1175/2009JPO4142.1

Carter GS, Gregg MC, Lien RC (2005) Internal waves, solitary-like waves, and mixing on the Monterey Bay shelf. Continental Shelf Research 25(12-13):14991520, DOI 10.1016/j.csr.2005.04.011

Cushman-Roisin B, Beckers JM (2011) Introduction to geophysical fluid dynamics: Physical and numerical aspects. Academic Press, Amsterdam

Cyr F, Bourgault D, Galbraith PS (2011) Interior versus boundary mixing of a cold intermediate layer. Journal of Geophysical Research 116(C12029):1-12, DOI 10.1029/2011JC007359

El-Sabh MI (1979) The Lower St. Lawrence Estuary as a physical oceanographic system. Le Naturaliste Canadien 106:55-73

Fer I, Widell K (2007) Early spring turbulent mixing in an ice-covered Arctic fjord during transition to melting. Continental Shelf Research 27(15):1980-1999, DOI 10.1016/j.csr.2007.04.003

Forrester WD (1970) Geostrophic approximation in the St. Lawrence Estuary. Tellus XXII(1):53-65

Forrester WD (1974) Internal tides in the St. Lawrence Estuary. Journal of Marine Research 32(1):55-66

Galbraith P, Chassé J, Gilbert D, Larouche P, Caverhill C, Lefaivre D, Brickman D, Pettigrew B, Devine L, Lafleur C (2014) Physical oceanographic conditions in the Gulf of St. Lawrence in 2013. DFO Canadian Science Advisory Secretariat 2014/062:vi + 84 p.

Galbraith PS (1992) Relating overturns to mixing and buoyancy flux. PhD thesis, Dalhousie University

Galbraith PS (2006) Winter water masses in the Gulf of St. Lawrence. Journal of Geophysical Research 111(C6):1-23, DOI 10.1029/2005JC003159

Garrett C, MacCready P, Rhines P (1993) Boundary mixing and arrested Ekman layers: Rotating stratified flow near a sloping boundary. Annual Review of Fluid Mechanics 25(1):291-323, DOI 10.1146/annurev.fl.25.010193.001451

Geyer WR, Smith JD (1987) Shear instability in a highly stratified estuary. Journal of Physical Oceanography 17:1668-1679

Geyer WR, Trowbridge JH, Bowen MM (2000) The dynamics of a partially mixed estuary. Journal of Physical Oceanography 30(2000):2035-2048 
Geyer WR, Scully ME, Ralston DK (2008) Quantifying vertical mixing in estuaries. Environmental Fluid Mechanics 8:495-509, DOI 10.1007/s10652-008-9107-2

Geyer WR, Lavery AC, Scully ME, Trowbridge JH (2010) Mixing by shear instability at high Reynolds number. Geophysical Research Letters 37(22):L22,607, DOI 10.1029/2010GL045272

Gilbert D, Pettigrew B (1997) Interannual variability (1948-1994) of the CIL core temperature in the Gulf of St. Lawrence. Canadian Journal of Fisheries and Aquatic Sciences 54(S1):57-67, DOI 10.1139/cjfas-54-S1-57

Godin G (1979) La marée dans le golfe et l'estuaire du Saint-Laurent. Le Naturaliste Canadien 106:105-121

Gregg M, Alford M, Kontoyiannis H, Zervakis V, Winkel D (2012) Mixing over the steep side of the Cycladic Plateau in the Aegean Sea. Journal of Marine Systems 89(1):30-47, DOI 10.1016/j.jmarsys.2011.07.009

Holtermann PL, Umlauf L, Tanhua T, Schmale O, Rehder G, Waniek JJ (2012) The Baltic Sea tracer release experiment: 1. Mixing rates. Journal of Geophysical Research 117(C1):1-17, DOI 10.1029/2011JC007445

Howard LN (1961) Note on a paper of John W. Miles. Journal of Fluid Mechanics 10(4):509-512

Ingram RG (1979) Internal wave observation off Isle Verte. Journal of Marine Research 36:715-724

Kay DJ (2003) Interfacial mixing in a highly stratified estuary 1. Characteristics of mixing. Journal of Geophysical Research 108(C3):3072, DOI 10.1029/ 2000JC000252

Koutitonsky VG, Bugden GL (1991) The physical oceanography of the Gulf of St. Lawrence: a review with emphasis on the synoptic variability of the motion. In: Therriault JC (ed) The Gulf of St. Lawrence: small ocean or big estuary?, vol 113, Canadian Special Publication of Fisheries and Aquatic Sciences 113, pp $57-90$

van der Lee EM, Umlauf L (2011) Internal wave mixing in the Baltic Sea: Near-inertial waves in the absence of tides. Journal of Geophysical Research 116(C10):1-16, DOI 10.1029/2011JC007072

Lie HJ, El-Sabh MI (1983) Formation of eddies and transverse currents in a twolayer channel of variable bottom with application to the Lower St. Lawrence Estuary. Journal of Physical Oceanography 13:1063-1075

MacKinnon JA, Gregg MC (2003) Mixing on the late-summer New England shelf - solibores, shear, and stratification. Journal of Physical Oceanography 33(7):1476-1492, DOI 10.1175/1520-0485(2003)033〈1476:MOTLNE $\rangle 2.0 . C O ; 2$

MacKinnon JA, Gregg MC (2005) Spring mixing : Turbulence and internal waves during restratification on the New England shelf. Journal of Physical Oceanography 35:2425-2443

Mertz G, Gratton Y (1990) Topographic waves and topographically induced motions in the St. Lawrence estuary. In: El-Sabh MI, Silverberg N (eds) Oceanography of a large-scale estuarine system: The St. Lawrence, vol 39, Springer-Verlag, New-York, chap 5, pp 94-108

Miles JW (1961) On the stability of heterogeneous shear flows. Journal of Fluid Mechanics 10(4):496-508

Moum JN, Caldwell DR, Nash JD, Gunderson GD (2002) Observations of boundary mixing over the continental slope. Journal of Physical Oceanography 32(7):2113-2130, DOI 10.1175/1520-0485(2002)032〈2113:OOBMOT $\rangle 2.0 . C O ; 2$ 
Moum JN, Perlin A, Klymak JM, Levine MD, Boyd T, Kosro P (2004) Convectively driven mixing in the bottom boundary layer. Journal of Physical Oceanography 34:2189-2202

Nepf HM, Geyer WR (1996) Intratidal variations in stratification and mixing in the Hudson estuary. Journal of Geophysical Research 101(C5):12,079-12,086

Osborn T (1980) Estimates of the local rate of vertical diffusion from dissipation measurements. Journal of Physical Oceanography 10:83-89

Palmer MR, Rippeth TP, Simpson JH (2008) An investigation of internal mixing in a seasonally stratified shelf sea. Journal of Geophysical Research 113(C12):1-14, DOI 10.1029/2007JC004531

Perlin A, Moum JN, Klymak JM, Levine MD, Boyd T, Kosro PM (2005) A modified law-of-the-wall applied to oceanic bottom boundary layers. Journal of Geophysical Research 110(C10):C10S10, DOI 10.1029/2004JC002310

Peters H (1997) Observations of stratified turbulent mixing in an estuary: Neapto-spring variations during high river flow. Estuarine, Coastal and Shelf Science 45(1):69-88, DOI 10.1006/ecss.1996.0180

Saucier FJ, Chassé J (2000) Tidal circulation and buoyancy effects in the St. Lawrence Estuary. Atmosphere-Ocean 38(4):505-556

Schafstall J, Dengler M, Brandt P, Bange H (2010) Tidal-induced mixing and diapycnal nutrient fluxes in the Mauritanian upwelling region. Journal of Geophysical Research 115(C10):C10,014, DOI 10.1029/2009JC005940

Shih LH, Koseff JR, Ivey GN, Ferziger JH (2005) Parameterization of turbulent fluxes and scales using homogeneous sheared stably stratified turbulence simulations. Journal of Fluid Mechanics 525:193-214, DOI 10.1017/ S0022112004002587

Slinn DN, Riley JJ (1996) Turbulent mixing in the oceanic boundary layer caused by internal wave reflection from sloping terrain. Dynamics of Atmospheres and Oceans 24:51-62

Smith GC, Saucier FJ, Straub D (2006) Formation and circulation of the cold intermediate layer in the Gulf of Saint Lawrence. Journal of Geophysical Research 111(C06011):1-18, DOI 10.1029/2005JC003017

Smyth WD, Moum JN, Caldwell DR (2001) The efficiency of mixing in turbulent patches: Inferences from direct simulations and microstructure observations. Journal of Physical Oceanography 31:1969-1992

Soulsby R (1997) Dynamics of marine sands: a manual for practical applications. Thomas Telford

St Laurent LC (2002) Estimating tidally driven mixing in the deep ocean. Geophysical Research Letters 29(23):2106, DOI 10.1029/2002GL015633

Taylor GI (1921) Tidal oscillations in gulfs and rectangular basins. Proceedings of the London Mathematical Society 20:148-181

Toole JM, Polzin KL, Schmitt RW (1994) Estimates of diapycnal mixing in the abyssal ocean. Science 264(5162):1120-1123

Umlauf L, Burchard H (2011) Diapycnal transport and mixing efficiency in stratified boundary layers near sloping topography. Journal of Physical Oceanography 41:329-346, DOI 10.1175/2010JPO4438.1

Walter RK, Woodson CB, Arthur RS, Fringer OB, Monismith SG (2012) Nearshore internal bores and turbulent mixing in southern Monterey Bay. Journal of Geophysical Research 117(C7):C07,017, DOI 10.1029/2012JC008115 
Wang J, Ingram RG, Mysak LA (1991) Variability of internal tides in the Laurentian Channel. Journal of Geophysical Research 96(C9):16,859-16,875, DOI 10.1029/91JC01580 
A1 Analytical solutions for the vertical modal structure of isopycnal displacements

In this appendix, we re-derive the analytical expression for the vertical modal structure of the Poincaré wave for the isopycnal displacements $\eta_{0}(z)$ given a analytical density profile (Eq. 6).

\section{A1.1 Problem formulation}

For a certain vertical mode $n, \eta_{0}$ is the solution of the ordinary differential equation (ODE) given by (e.g., Cushman-Roisin and Beckers, 2011):

$$
\frac{d^{2} \eta_{0}}{d z^{2}}+\left(\frac{N^{2}-\sigma^{2}}{c_{n}^{2}}\right) \eta_{0}=0
$$

where $N^{2}=\frac{g}{\rho} \frac{\partial \rho}{\partial z}=\frac{g d}{(z+h)^{2}}$ given the density profile imposed by Equation 6, and $c_{n}$ the phase velocity that, as we will show later, depends on the vertical mode $n$. If we let $\nu^{2}=\frac{g d}{c_{n}^{2}}$, and neglecting $\sigma^{2}$ because $N^{2}>>\sigma^{2}$, Equation A1 can be re-written:

$$
\frac{d^{2} \eta_{0}}{d z^{2}}+\frac{\nu^{2}}{(z+h)^{2}} \eta_{0}=0
$$

A1.2 Simplifications and general solution of the problem

To resolve the problem, we start by introducing two successive variable changes in order to scale the equation. We first introduce the non-dimensional parameter $\xi$ such as $z=\xi h\left(d \xi=\frac{1}{h} d z\right)$. Then, if we let $\zeta=\xi+1(d \zeta=d \xi)$, the ODE becomes:

$$
\frac{d^{2} \eta(z)}{d \zeta^{2}}+\frac{\nu^{2}}{\zeta^{2}} \eta=0
$$

We now assume that the solution has the form $\eta_{0}(\zeta)=A(\zeta) B(\zeta)$. After applying the derivative rules, the ODE is now:

$$
\begin{aligned}
& A \frac{d^{2} B}{d \zeta^{2}}+2 A_{\zeta} \frac{d B}{d \zeta}+A_{\zeta \zeta} B+\frac{\nu^{2}}{\zeta^{2}} A B=0 \\
& \frac{d^{2} B}{d \zeta^{2}}+\frac{2 A_{\zeta}}{A} \frac{d B}{d \zeta}+B\left[\frac{A_{\zeta \zeta}}{A}+\frac{\nu^{2}}{\zeta^{2}}\right]=0 .
\end{aligned}
$$

where subscripts to variable $A$ stand for derivative relative to $\zeta$. The passage from the first to the second line of Equation A4 was made by multiplying by $1 / A$.

We now choose $A=\zeta^{1 / 2}$. Knowing that: 


$$
\begin{aligned}
A_{\zeta} & =\frac{1}{2 \zeta^{1 / 2}}, \\
A_{\zeta \zeta} & =\frac{-1}{4 \zeta^{3 / 2}}, \\
\frac{A_{\zeta}}{A} & =\frac{1}{2 \zeta} \text { and } \\
\frac{A_{\zeta \zeta}}{A} & =\frac{-1}{4 \zeta^{2}},
\end{aligned}
$$

and by multiplying Equation A4 by $\zeta^{2}$, the ODE becomes:

$$
\zeta^{2} \frac{d^{2} B}{d \zeta^{2}}+\zeta \frac{d B}{d \zeta}+B\left[\nu^{2}-\frac{1}{4}\right]=0 .
$$

We now introduce a new variable change $s=\ln (\zeta)$ (thus $\zeta=e^{S}$ ) which results in the following derivation rules:

$$
\begin{aligned}
\frac{d s}{d \zeta} & =\frac{1}{\zeta}=e^{-s} \\
\frac{d}{d \zeta} & =e^{-s} \frac{d}{d s} \text { and } \\
\frac{d^{2}}{d \zeta^{2}} & =e^{-2 s}\left[\frac{d^{2}}{d s^{2}}-\frac{d}{d s}\right] .
\end{aligned}
$$

With this variable change, the equation is:

$$
\frac{d^{2} B}{d s^{2}}+\left[\nu^{2}-\frac{1}{4}\right] B=0
$$

This last expression is a second-order homogeneous differential equation with constant coefficients that can be resolved with standard procedures (see any ODE textbook). The characteristic equation for this equation is $\lambda^{2}+\mu^{2}=0$, where $\mu^{2}=\nu^{2}-\frac{1}{4}$. Since $\mu^{2}$ is positive by construction (this can be easily verified later), the characteristic equation leads to complex roots $\lambda= \pm i \mu$. In this case, the analytical solution for the variable $B$ has the form:

$$
B=C_{1} \cos (\mu s)+C_{2} \sin (\mu s)
$$

where $C_{1}$ and $C_{2}$ are constant coefficients to be determined.

A1.3 Specific solutions given the boundary conditions

Recalling that $\eta_{0}(\zeta)=A(\zeta) B(\zeta)$ and $A(\zeta)=\zeta^{1 / 2}$, we can now use the boundary conditions on $\eta_{0}$ to find the specific solution of our problem. Because displacements are vertically limited by the seafloor and the surface, the boundary conditions are $\eta_{0}(z=0)=0$ and $\eta_{0}(z=H)=0$, where $H=300 \mathrm{~m}$ is the total depth. Given the variables changes made in the preceding, these boundary conditions imply $B(s=0)=0$ (i.e., $z=0 \rightarrow \zeta=1 \rightarrow s=0$ ) and $B\left(s=\ln \left(\frac{H}{h}\right)+1\right)=0$ (i.e., $\left.z=0 \rightarrow \zeta=\frac{H}{h}+1 \rightarrow s=\ln \left(\frac{H}{h}+1\right)\right)$. 
The first boundary condition (at the surface) implies that $C_{1}=0$, while the second condition implies that the argument under the sine must be of the form $\mu s=n \pi$, with $n=1,2, \ldots$, an integer corresponding to the $\mathrm{n}^{\text {th }}$ vertical mode. Substituting $s=\ln \left(\frac{H}{h}+1\right)$ in the preceeding, a necessary condition is that:

$$
\mu=\frac{n \pi}{\ln \left(\frac{H}{h}+1\right)} .
$$

After replacing all terms by their expressions in $z$ and taking into consideration these boundary conditions, Equaion A9 becomes:

$$
\eta_{0}(z)=\eta_{n}\left(\frac{z}{h}+1\right)^{1 / 2} \sin \left[\frac{\ln \left(\frac{z}{h}+1\right)}{\ln \left(\frac{H}{h}+1\right)} n \pi\right] .
$$

Note that in the last expression, $C_{2}$ has been replaced by $\eta_{n}$ for clarity and is the parameter that carries the dimension $(\mathrm{m})$ of $\eta_{0}$. This constant parameter is determined by fitting Equation A11 to observations. Note also that Equation A11 is slightly different than the one presented in Forrester (1974) (its Equation 10), but by carefully adjusting the constant parameters in Forrester's equation, we can show that both equations give the same structure.

Another consequence of the second boundary condition (Eq. A10) is that it gives conditions on the phase velocity $\left(c_{n}\right)$ of the admissible Poincaré waves. Replacing $\mu$ by its expression in $z$ this equation leads to:

$$
c_{n}^{2}=\frac{g d}{\left(\frac{n \pi}{\ln \left(\frac{H}{h}+1\right)}\right)^{2}+\frac{1}{4}} .
$$

This expression is necessary for the dispersion relation presented in Equation 5. 


\begin{tabular}{lc}
\hline & $\mathbf{N 0 8 0}$ \\
\hline total depth $(\mathrm{m})$ & 83 \\
ADCP depth (frequency, orientation) & $59(600 \mathrm{kHz}$, down $)$ \\
ADCP range (m) & 61 -bottom \\
ADCP sampling freq. (Hz) & $\frac{1}{3}$ \\
thermistors depth $(\mathrm{m})$ & $30,40,50,60,65,70,75,80$ \\
thermistor sampling freq. $(\mathrm{Hz})$ & $0.2,0.2,0.2,0.1,0.1,0.1,0.1,0.1$ \\
\hline
\end{tabular}

Table 1 Mooring information

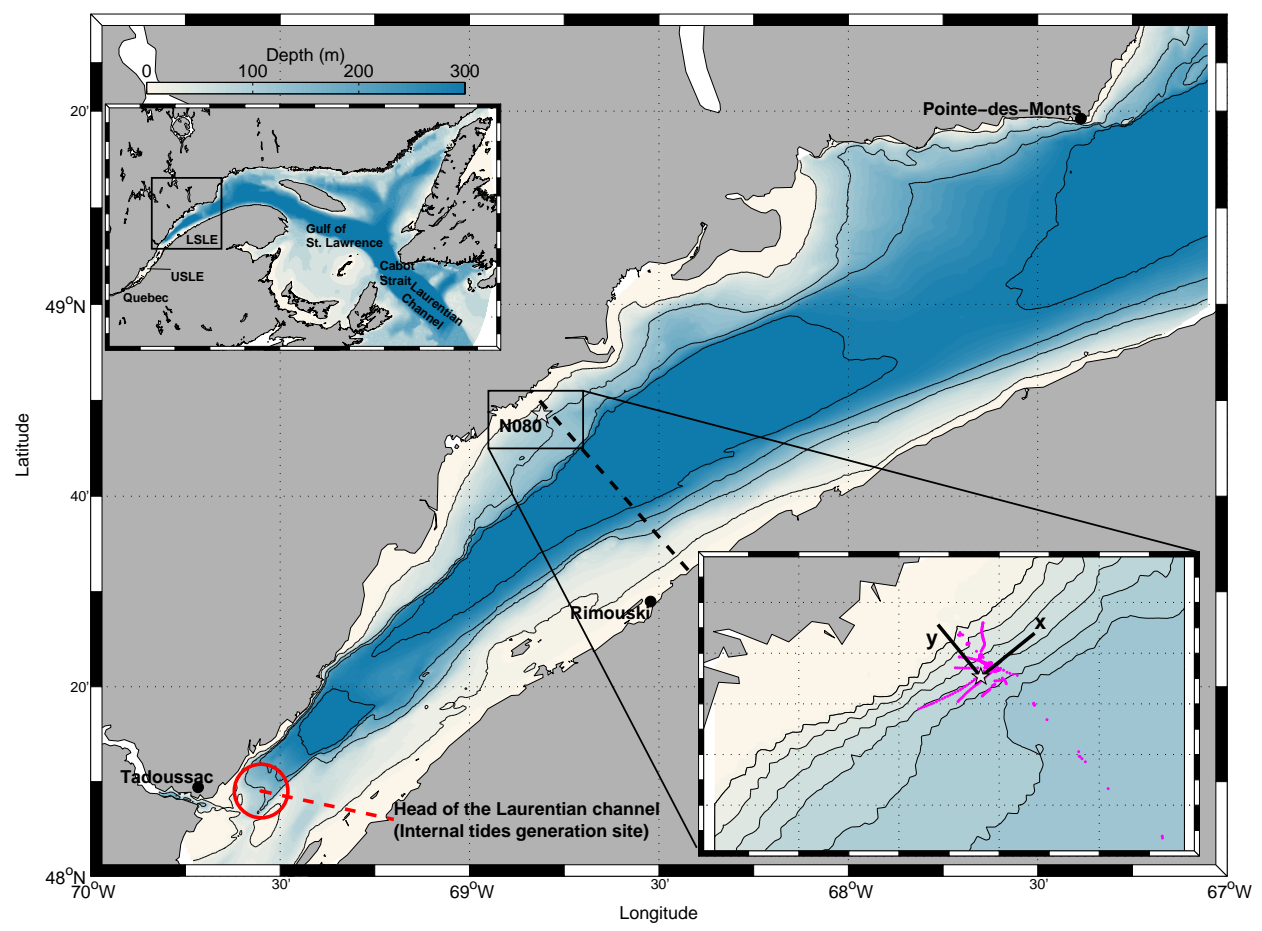

Fig. 1 Bathymetry of the Gulf of St. Lawrence (upper inset) and the Upper (USLE) and Lower St. Lawrence Estuary (LSLE). The square box in the upper inset correspond to the LSLE where the study was realized (main figure). Isobaths 20, 120, 200 and $300 \mathrm{~m}$ have been added. The dashed-line is the Rimouski section across the estuary. Second inset shows details of the study area on the northern portion of the transect, between isobaths 20-120 m (shown with $20 \mathrm{~m}$ intervals). Positions of mooring N080 (white star) and of the 322 VMP profiles used in this study (purple dots) are also presented. 

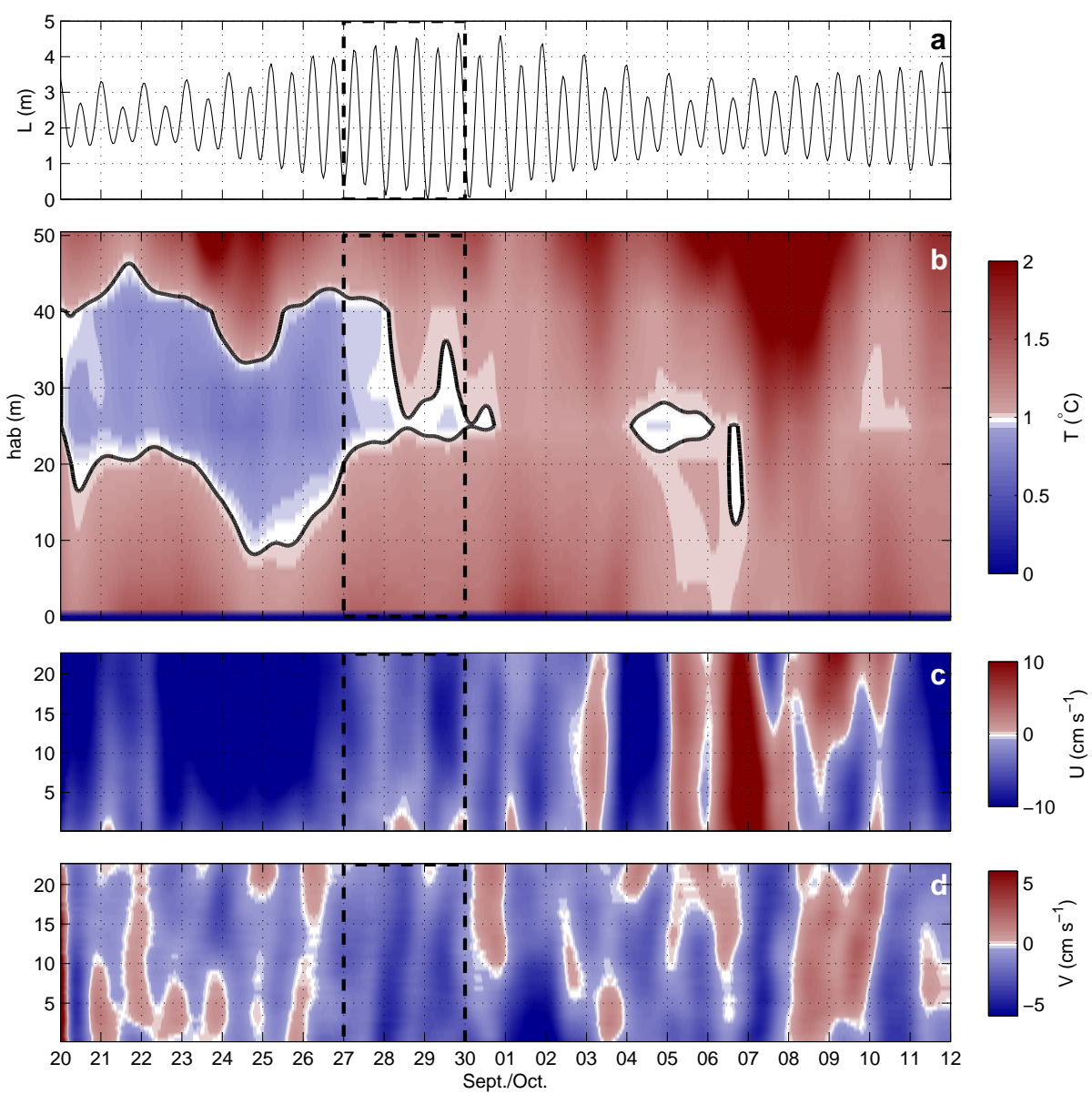

Fig. 2 Temperature and currents measured for the duration of the mooring deployment. (a) Predicted tide water level at Rimouski $(L)$. (b) Evolution of the temperature field for this period as measured by the thermistor chain. Temperature was linearly interpolated between thermistors and a 25-hour low-pass filter has been applied (fourth-order Butterworth filter). Solid lines are $T=1{ }^{\circ} \mathrm{C}$ contours. (c-d) Respectively the along- and cross-shore velocities measured by the ADCP over the slope. The 25-hour low-pass filter has also been applied on both current components. The vertical axis for the three last panels is the height above bottom $(h a b)$. Dashed-boxes in each panels correspond to the time period presented in Figure 3. 

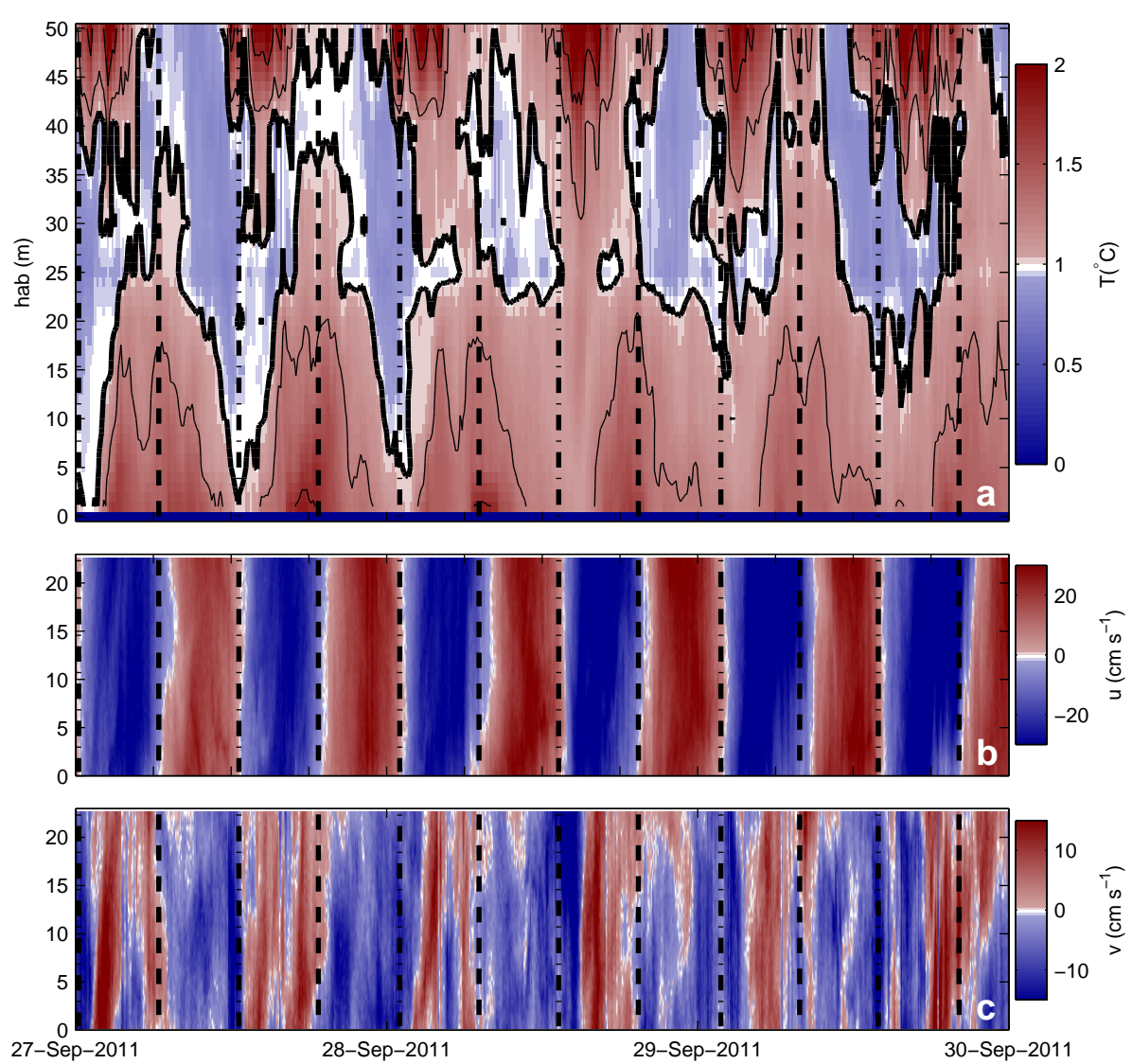

Fig. 3 Example of a timeseries from the mooring for temperature $(T)$, along- and crossshore velocities for a three-day period, 27-30 September 2011. The temperatures are 10-minute averaged and linearly interpolated between each thermistors, while the velocities are 10-minute averaged and raw in the vertical $(0.5 \mathrm{~m})$. Thick solid lines in (a) are $T=1^{\circ} \mathrm{C}$ contours while thin lines are $T=1.25$ and $1.75^{\circ} \mathrm{C}$. High tides (dashed-lines) and low tides (dashed-dot lines) are also identified in all panels for reference. 
a
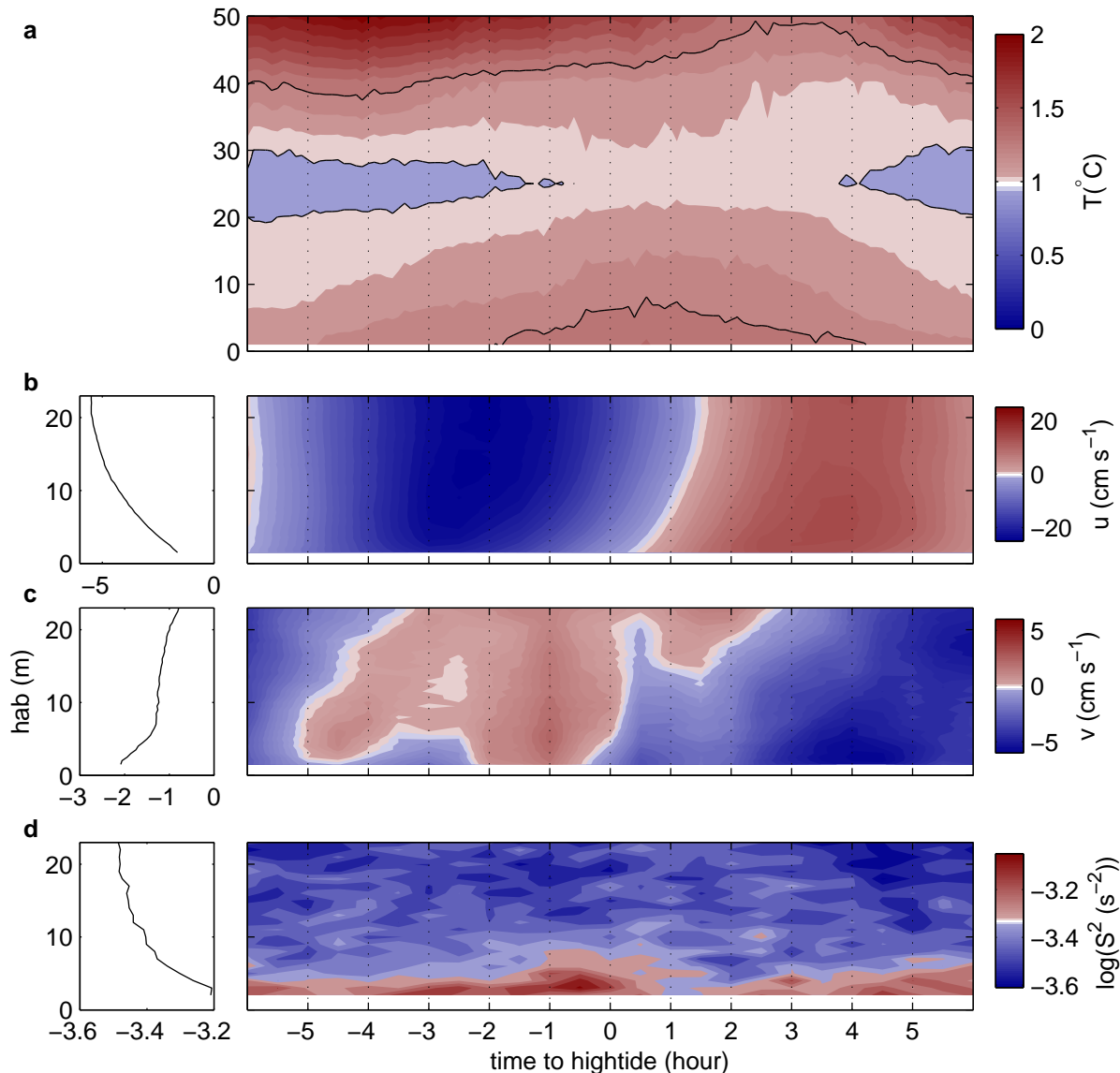

Fig. 4 Mooring conditions relative to the $\mathrm{M}_{2}$ tide cycle. All fields have been averaged in 15-minute classes relative to the high tide. The vertical axis is the height above bottom $(h a b)$. (a) Temperature field, with isotherms $1^{\circ} \mathrm{C}$ and $1.3^{\circ} \mathrm{C}$ (black lines) added for visual reference. (b) and (c), along- and cross-shore velocities, with $0.5 \mathrm{~m}$ vertical bins. (d) Base-10 log of the mean shear $S^{2}$. Note that panel $a$ spans $50 \mathrm{~m}$ on the vertical while others span only $25 \mathrm{~m}$. Left side panels in bcd are the time-averaged profiles. 

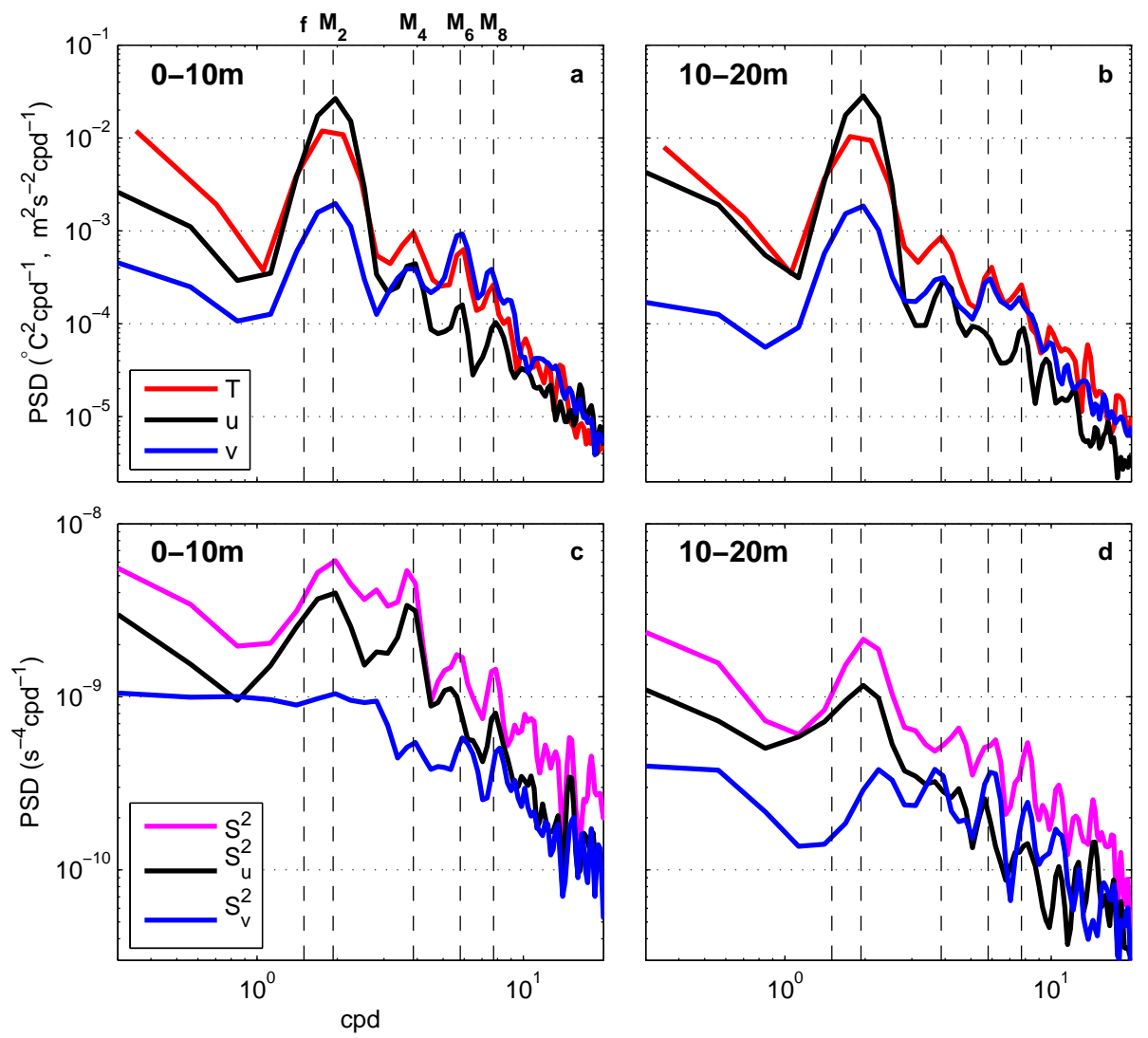

Fig. 5 Power spectrum density (PSD) for temperature, cross-shore $(u)$ and along-shore $(v)$ velocities, vertically-averaged over the depth range 0-10 $\mathrm{m}$ (a) and 10-20 m (b) above the seabed. (c-d) Power spectrum density for the total shear $\left(S^{2}\right)$, along-shore $\left(S_{u}^{2}=\left(\frac{\partial u}{\partial z}\right)^{2}\right)$ and crossshore shear $\left(S_{v}^{2}=\left(\frac{\partial v}{\partial z}\right)^{2}\right)$ for the same depth ranges. The frequency is in cycle per day (cpd). Tidal Harmonics $\mathrm{M}_{2}, \mathrm{M}_{4}, \mathrm{M}_{6}$ and $\mathrm{M}_{8}$ have been added for reference (vertical dashed-lines). The choice of the window used for PSD calculations (Hanning window of $\sim 2.2$ days) makes the inertial frequency $f$ difficult to distinguish from $\mathrm{M}_{2}$ 


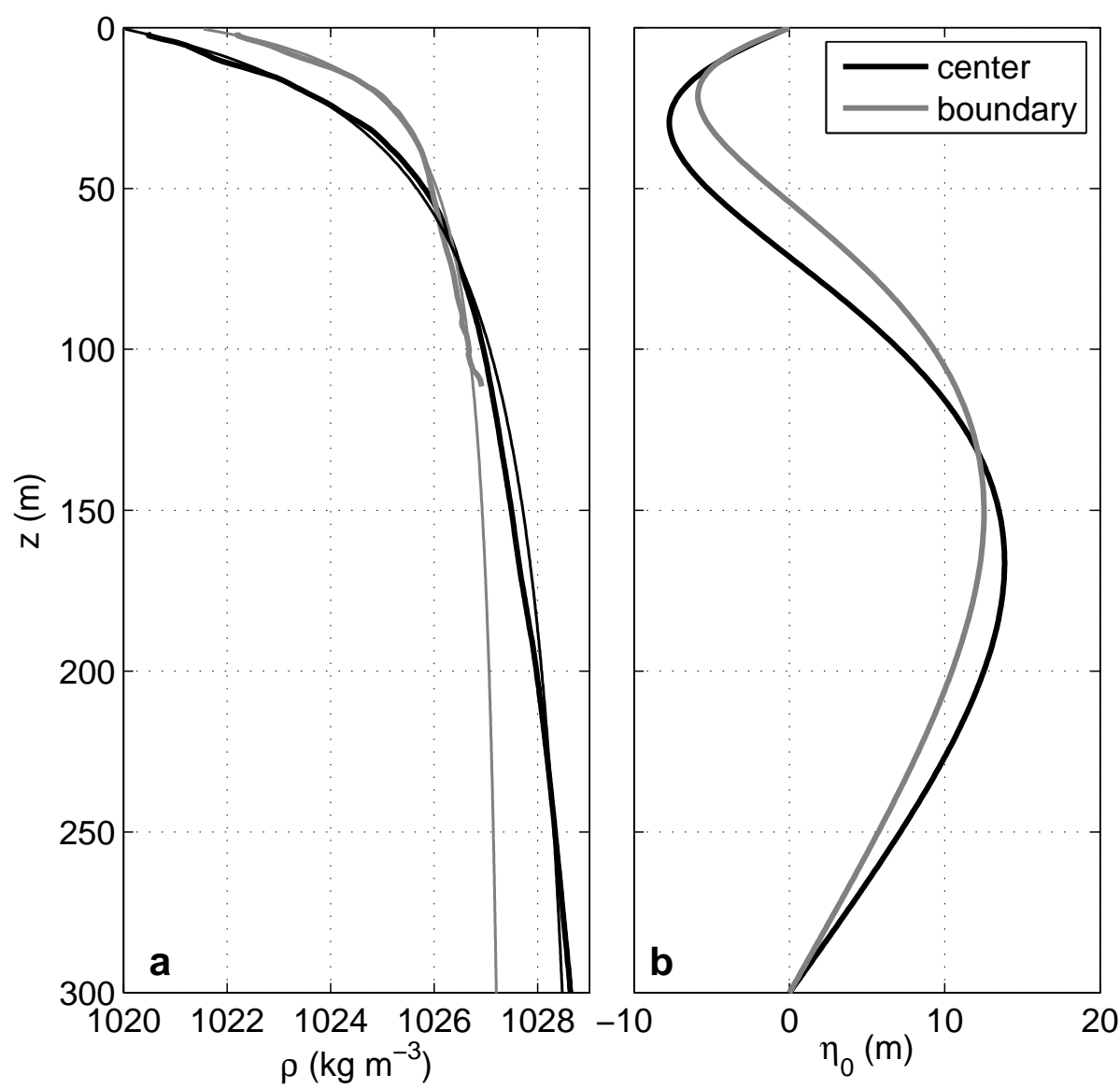

Fig. 6 Vertical density structure of the LSLE at the sampling section and predicted vertical displacement of the internal tide. (a) Average density profiles (thick lines) at the center of the channel (black) and at the mooring site (gray) during mooring deployment period. The thin lines are the exponential fits (Eq. 6) of both profiles, respectively. (b) Vertical mode-2 for vertical displacement of isopycnals obtained from the exponential fits of panel $a$. 


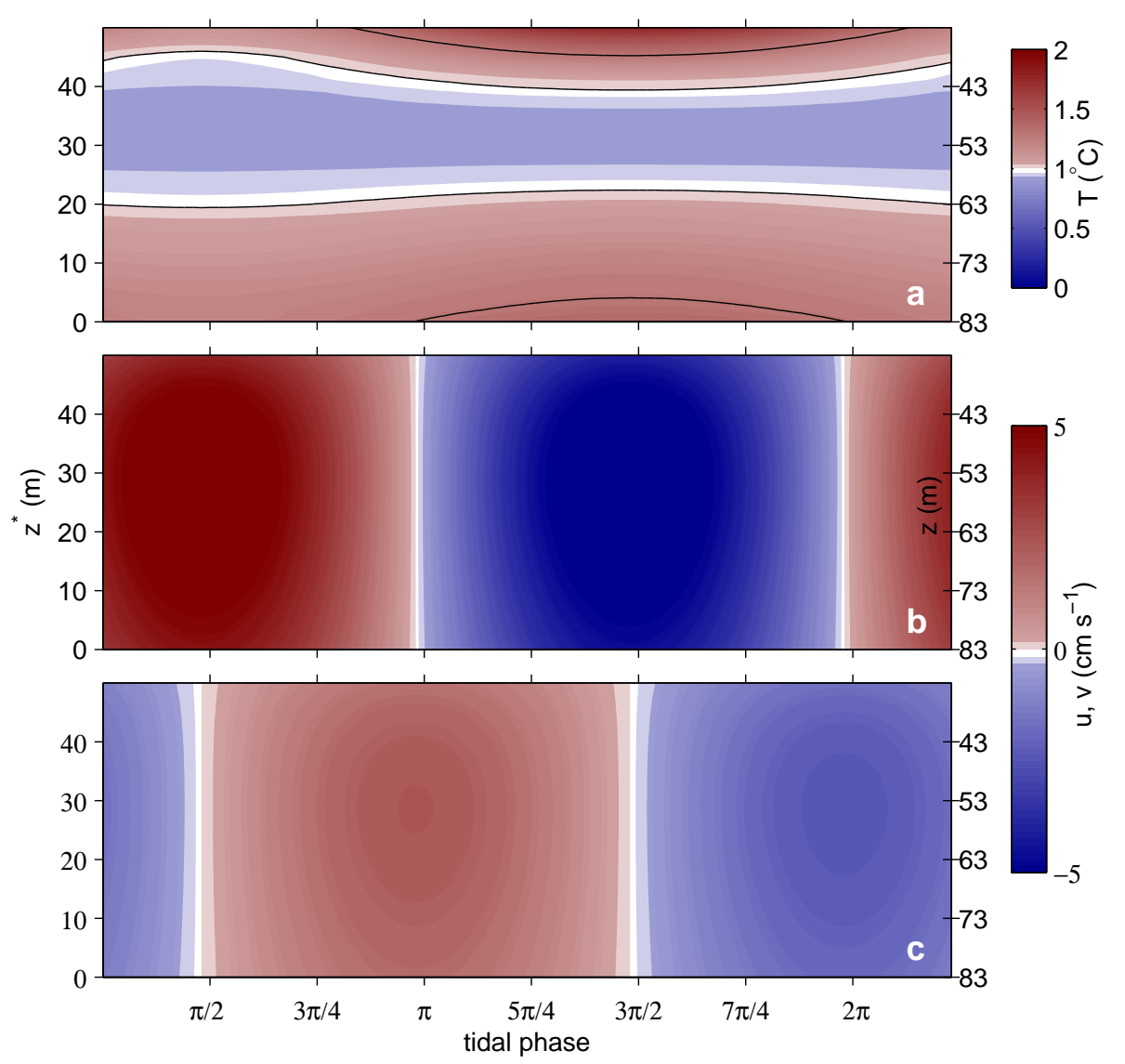

Fig. 7 Predicted temperature $(T)$, along- $(u)$ and cross-shore $(v)$ velocities evolution during a $\mathrm{M}_{2}$ tide cycle for an idealized mode-2 Poincaré internal tide (Equations 4 and 8) for approximate mooring location $(y=33.9 \mathrm{~km})$ and its depth span. For better comparison with Figure 4, the left-hand side vertical axis is $z *=z_{0}-z$, where $z_{0}=83 \mathrm{~m}$ is the total depth at mooring location. The horizontal axis also starts at $\phi=\frac{\pi}{4}$ instead $\phi=0$ for the same reason. The water column depth $z$ is provided as the right-hand vertical axis of the figure. Isotherms $T=1^{\circ} \mathrm{C}$ and $T=1.3^{\circ} \mathrm{C}$ have also been added in panel $a$ (black lines). 

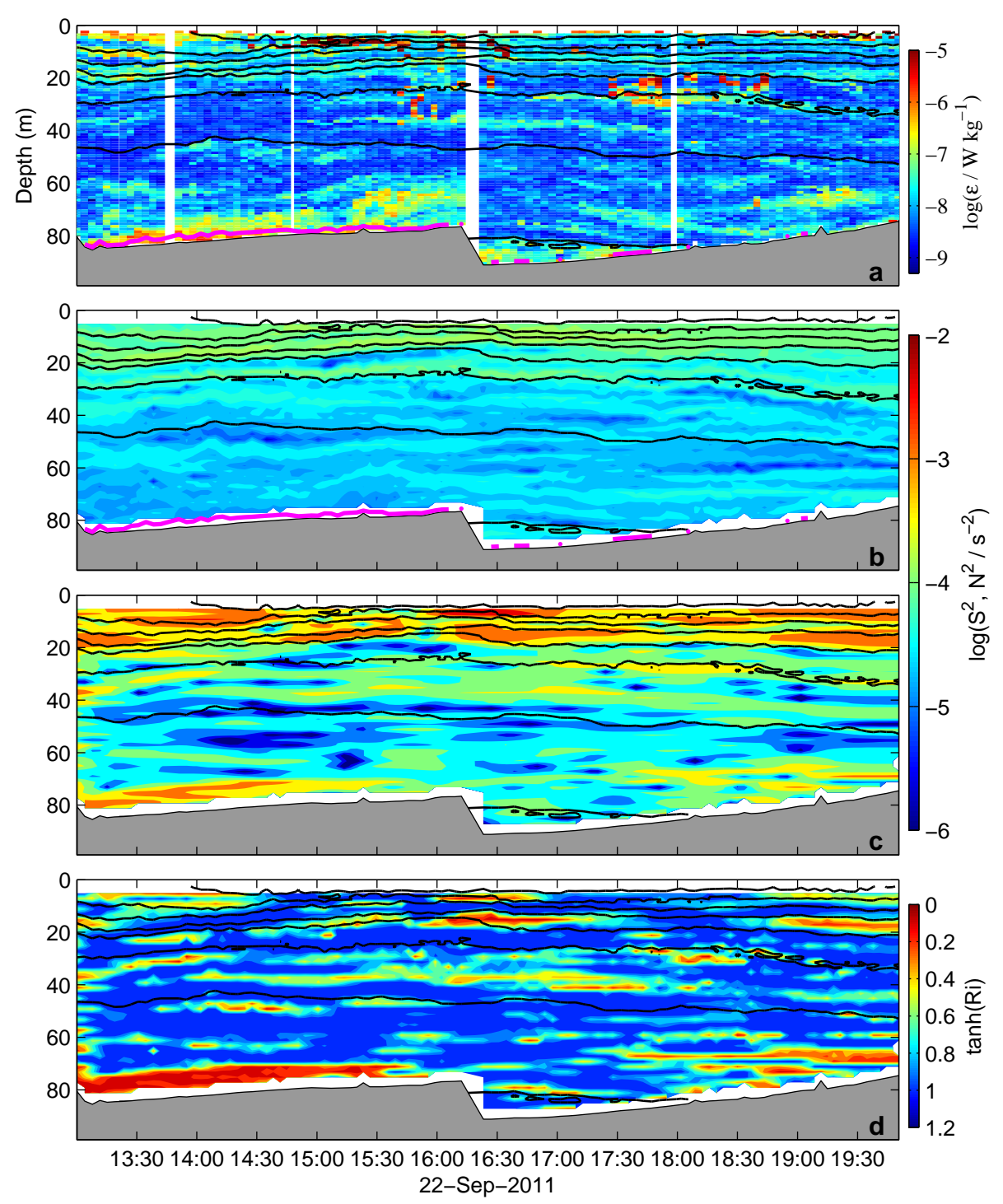

Fig. 8 Turbulence versus water column stability parameters as a function of time and depth (m) in proximity of the mooring on September 22, 2011, measured from a drifting boat (repositioned at 16:13). (a) Dissipation rate of turbulent kinetic energy $(\epsilon)$. (b) Background buoyancy frequency squared in 4-m bins $\left(N^{2}\right)$. (c) Background shear squared in 4-m bins $\left(S^{2}\right)$. (d) 4-m scale Richardson number $(R i)$. Black lines in all panels indicate isopycnals. Magenta lines in panels $a$ and $b$ indicate regions near the bottom where $l_{o}>\kappa \tilde{z}$ (see Section 5.3). 

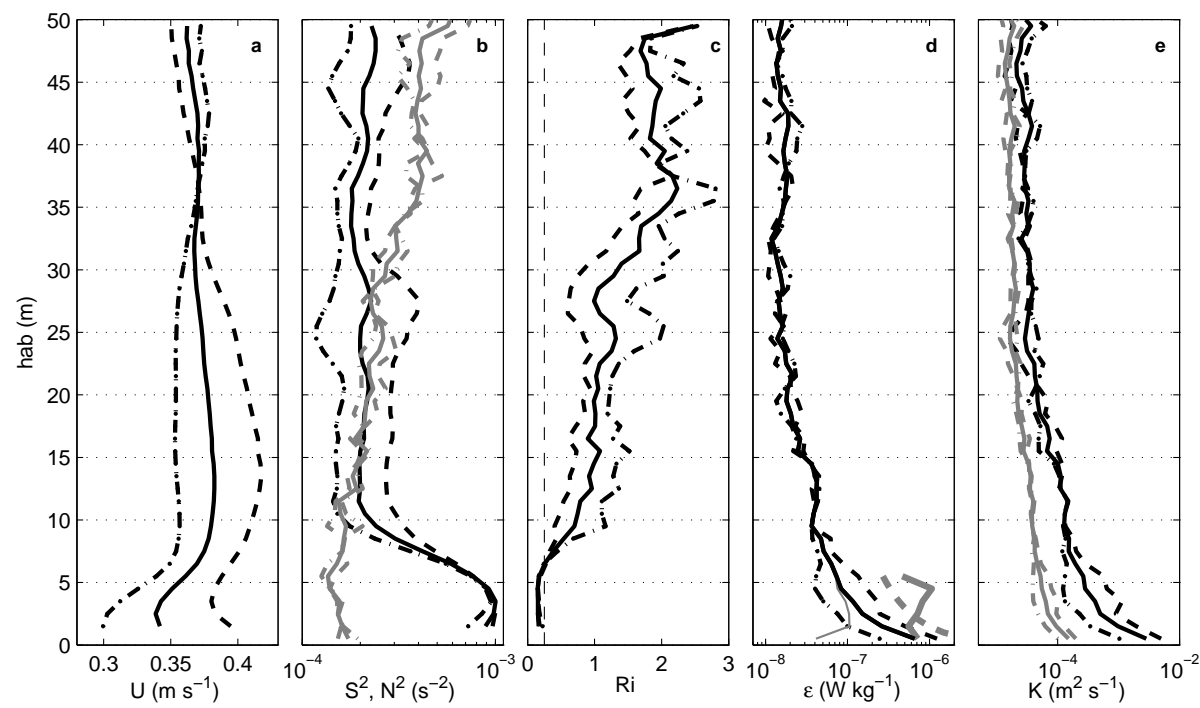

Fig. 9 Averaged quantities of our 322 VMP casts (solid lines). Averaged profiles when considering only flood (dashed) and ebb (dot-dashed) are also presented. (a) Velocity profiles $U=\sqrt{u^{2}+v^{2}}$ from the ADCP deployed outboard, corresponding to VMP casts. (b) Shear $\left(S^{2}\right.$, black lines) calculated with velocity profiles from outboard ADCP, and stratification $\left(N^{2}\right.$, gray lines) from VMP casts. (c) Richardson number $\left(R i=\frac{N^{2}}{S^{2}}\right)$ calculated from the ratio of mean profiles of panel $b$. (d) Dissipation rate of TKE when using all available bins (thick black lines) and bins when the size of overturns is limited by the stratification, e.g., when $l_{O}<\kappa \tilde{z}$ (thin gray line). Also on this panel, the dissipation when the size of overturns is not limited by the stratification $\left(l_{o}>\kappa \tilde{z}\right.$, thick gray line) and the dissipation inferred from near bottom velocities using the log-law scaling presented in section $5.3\left(\tilde{\epsilon}=\frac{u_{*}^{3}}{\tilde{z}}\right.$, dashed-gray line). (e) Turbulent diffusivity calculated using a constant $(\Gamma=0.2$, black lines) and variable (Eq. 3, gray lines) flux parameter. Except $U$, averaged profiles are calculated assuming log-normal distribution. 

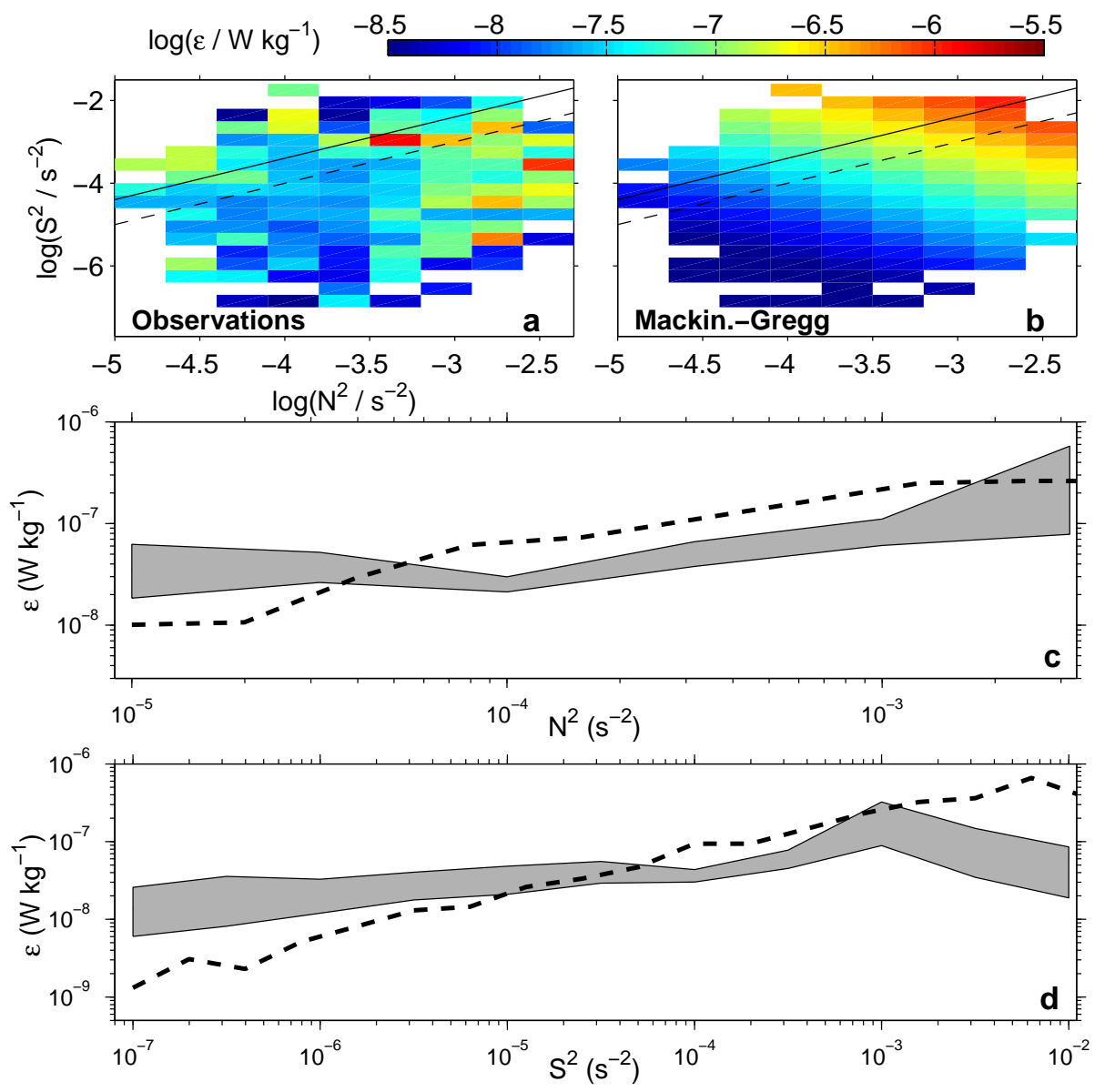

Fig. 10 Dissipation rates of turbulent kinetic energy as a function of the buoyancy frequency squared $\left(N^{2}\right)$ and of the shear squared $\left(S^{2}\right)$. (a) Observations from all 322 profiles with bottom $10 \mathrm{~m} \mathrm{hab}$ and top $5 \mathrm{~m}$ removed. The solid and dashed-lines are respectively $R i=1$ and $R i=\frac{1}{4}$. (b) Same as $a$, for MacKinnon and Gregg (2003) scaling $\epsilon_{\mathrm{MG}}$ (Eq. 9). (c-d) Respectively the vertical and horizontal averages of the two panels above to highlight the effect of the buoyancy frequency and the shear on dissipation. The shaded areas are the bootstrapped $95 \%$ confidence interval on observations (panel $a$ ) while the dashed-black lines are the averages of the predicted $\epsilon_{\mathrm{MG}}($ panel $b)$. 